\title{
ANÁLISIS DE LA PARTICIPACIÓN DE LOS JUGADORES DE VOLEIBOL MASCULINO DE ALTO NIVEL MUNDIAL EN LAS ACCIONES TERMINALES DEL JUEGO
}

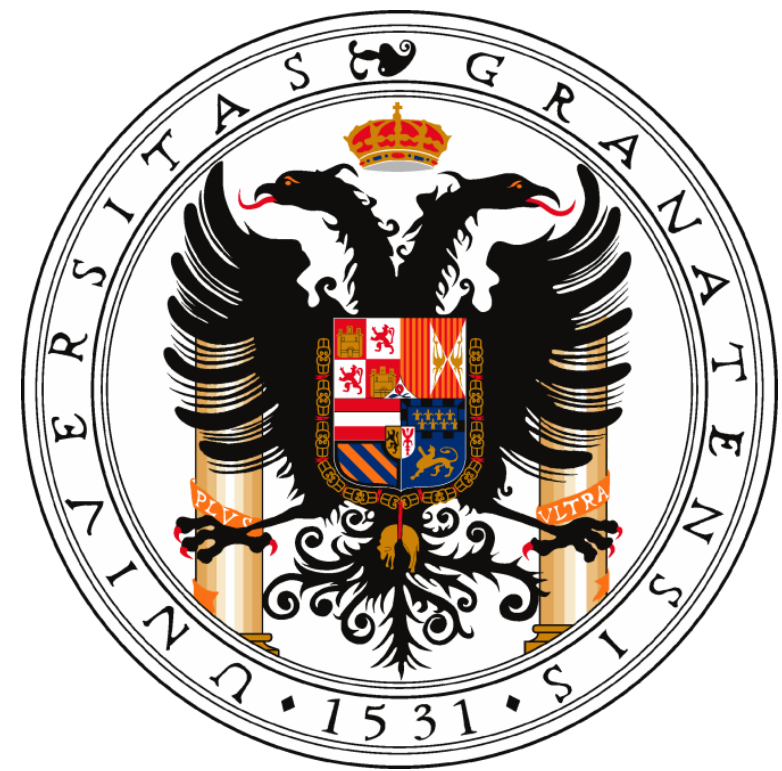

Autor: Antonio Millán Sánchez

Codirectores: Aurelio Ureña Espá

Dep. de Educación Física y Deportiva

Pedro Femia Marzo

Dep. de Estadística e I.O.

Departamento de Educación Física y Deportiva

Facultad de Ciencias del Deporte

Universidad de Granada

Máster de Investigación en Actividad Física y Deporte Trabajo Fin de Máster 


\section{Índice}

Resumen

Abstract

Introducción

Método

Muestra

Procedimiento .10

Instrumento de registro

Validez y fiabilidad .13

Control de sesgos . .13

Análisis estadístico

Resultados

Intervención de los jugadores en las acciones finales a medida que avanzan los sets de forma general

Participación de los jugadores en las acciones finales a medida que avanza cada uno de los sets

Intervención de los jugadores en las acciones finales a medida que avanza el partido de forma global

Participación de los diferentes jugadores en las acciones terminales positivas a medida que se desarrolla el partido

Participación de los diferentes jugadores en las acciones terminales negativas a medida que se desarrolla el partido

Acciones terminales a medida que avanza el partido ……………………………................25

Relación entre el jugador que ejecuta la acción terminal y la rotación...................................25

Factores que afectan a la probabilidad de ganar el punto

Discusión

Conclusiones. 
Análisis de la participación de los jugadores de voleibol masculino de alto nivel mundial en las acciones terminales del juego

Agradecimientos

.36

Referencias

Anexos .40 


\section{Resumen}

Con el presente estudio se pretendió analizar la participación de los jugadores de voleibol en las acciones que generan puntos a lo largo del partido, así como su relación con el resultado. Se recogieron las acciones terminales clasificadas en función de la acción técnica que provocó ganar o perder el punto. El orden de la jugada y el set sirvieron para discriminar el momento del partido. Los jugadores fueron seleccionados por su puesto específico y su función. Además, se tuvieron en cuenta dos criterios contextuales como la rotación y la acción de remate delantera o zaguera. Para ello se analizaron 5790 acciones finales pertenecientes a 23 partidos del Campeonato del Mundo masculino de voleibol disputado en Italia (2010). De forma general, el número de jugadores que intervinieron en las acciones terminales no se vio alterado a medida que se desarrollaron el partido y los sets, pero sí hubo resultados significativos $(p<0,05)$ en lo que respecta al primer set de los partidos en particular en algunos jugadores y algunas fases del mismo. El tipo de acción terminal ejecutada no guardó relación con el periodo del partido en el que se produce. Los resultados indicaron asociación estadística $(p<0,001)$ entre el jugador que participó en las acciones finales y la rotación del equipo, encontrándose que hasta el $80 \%$ de las acciones terminales fueron ejecutadas por los jugadores que se encontraban en la zona delantera. Además, los factores más importantes $(p<0,001)$ para aumentar la probabilidad de conseguir puntos fueron que la acción terminal la ejecutara el opuesto (seguido por receptor, central y colocador) desde la zona delantera, un resultado relevante, tratándose del más alto nivel internacional masculino, al señalar la influencia menor del atacante opuesto en la zona zaguera con respecto al resto de atacantes cuando son delanteros.

Palabras clave: participación, acciones terminales, puesto específico, rotación, análisis del juego, voleibol. 


\section{Abstract}

With this study we aimed to analyze the participation of volleyball players in the actions of the game which generate points, as well as its relationship to the result. Terminal actions were registered based on the technical action that caused the win or loss of points. The order of the point and set were used for differentiating the moment of the game. Players were classified based on their position and function. Furthermore, rotation and action location (front or back row) were considered as contextual criteria. In order to do so, 5790 terminal actions from 23 matches of the 2010 FIVB Men's Volleyball World Championship, which took place in Italy, were analyzed. The amount of players involved in performing terminal actions was not modified as the sets and matches drew on, but significant results were found regarding the first set of the matches $(p<0,05)$, particularly some players in some phases of it. The type of terminal action performed was not related to the period of the match in which it was carried out. The results showed a statistical association $(p<0,001)$ between the player who performed the terminal action and the team rotation, being that up to $80 \%$ of terminal actions were executed by players in the front row. Furthermore, the most important factors $(p<0,001)$ in order to win points were, regarding player position, to be an opposite hitter (followed by receiver, middle blocker and setter) from the front row, a result which is relevant in the male top-level volleyball, pointing out the smaller influence of the opposite attacker from the back row with respect to the other attackers from the front row.

Key words: participation, terminal actions, player position, rotation, match analysis, volleyball. 


\section{Introducción}

La información que aporta al entrenador el análisis estadístico de las grabaciones de su equipo determina las ventajas y desventajas de los conjuntos y jugadores (Byra y Scott, 1983). Este análisis puede usarse para obtener información tanto del equipo propio como del rival (Häyrinen, Hoivala, y Blomqvist, 2004).

Las acciones terminales o finales son aquéllas que pueden representar el final de un punto, por lo que existen gran cantidad de estudios que intentan determinar cuáles de estas acciones tienen mayor efecto sobre el resultado en el voleibol internacional de máximo nivel (Häyrinen et al., 2004; Zetou, Moustakidis, Tsigilis, y Komninakidou, 2007), encontrándose numerosos estudios en categoría masculina, al ser indicadoras de la victoria o derrota (Marcelino, Mesquita, y Afonso, 2008; Marcelino, Mesquita, y Sampaio, 2009; Marelić, Rešetar, y Janković, 2004; Palao, Santos, y Ureña, 2004a; Rodríguez-Ruiz et al., 2011).

Estas acciones pueden ser el servicio, el ataque o el bloqueo (Clemente, Antonio, Moreno Domínguez, y Moreno Arroyo, 2005), en las que se busca acabar la jugada, pero también las llamadas acciones de continuidad (Marcelino et al., 2009), es decir, la recepción (Marelić et al., 2004), la defensa (Mesquita, Manso, y Palao, 2007; Monteiro, Mesquita, y Marcelino, 2009) y la colocación (Marcelino et al., 2009) pueden representar el final de un punto cuando son ejecutadas de forma errónea.

Sin embargo, el recuento de datos de forma general en partidos entre equipos tan igualados como los del voleibol de máximo nivel (Häyrinen et al., 2004) no proporciona información de verdadero interés. Por ello a la hora del análisis puede ser importante discriminar los resultados obtenidos en función del tipo de set, ya que como muestran estudios en otros deportes (Sampaio, 1998) la diferencia de puntos en el marcador puede alterar la estructura del partido. Así, en los partidos más igualados, las variables que predicen la victoria y derrota difieren normalmente de aquéllos más desequilibrados (Lorenzo Calvo, Gómez Ruano, Ortega Toro, Ibañez Godoy, y Sampaio, 2010). Además, también existen diferencias en el rendimiento de los equipos en función del número de sets jugados (Marcelino et al., 2009).

Analizando las acciones finales de forma particular, encontramos que la más importante a la hora de acabar los puntos es el ataque (Häyrinen et al., 2004; Marelić et al., 2004; Palao et al., 2004a; Rodríguez-Ruiz et al., 2011; Zetou et al., 2007), pero la efectividad del ataque depende de las acciones inmediatamente anteriores, ya sean recepción (Häyrinen et al., 2004; Rodríguez-Ruiz et al., 2011; Zetou et al., 2007) o defensa (Häyrinen et al., 2004; Monteiro et al., 2009) y colocación (Rodríguez-Ruiz et al., 2011). Si bien el rendimiento de la defensa no está asociado a la victoria o derrota en el set, su eficacia en la fase de contraataque es fundamental para obtener un ataque con éxito (Monteiro et al., 2009). 
En un segundo escalón se sitúa el bloqueo (Häyrinen et al., 2004), que ofrece la mayor diferencia entre puntos obtenidos en sets ganados y perdidos (Palao et al., 2004a; Rodríguez-Ruiz et al., 2011), por lo que se puede considerar como el elemento técnico diferenciador entre los equipos de más alto nivel y aquéllos de menor rendimiento (Marcelino et al., 2008; Palao et al., 2004a).

Por el orden lógico en que tienen lugar las acciones en voleibol, a menudo están relacionadas; así, se conoce que los equipos con más puntos conseguidos directamente con el saque son también los que obtienen más tantos con el bloqueo (Marcelino et al., 2008), lo que hace suponer que las posibilidades de bloqueo con éxito aumentan de forma proporcional al riesgo asumido con el saque (Marelić et al., 2004). En este sentido, en categorías de formación, se ha encontrado que un saque con mayor riesgo y potencia dificulta la construcción del ataque en el equipo receptor (Ureña, Vavassori, LeónRodríguez, y González-Ortiz, 2011), si bien a este nivel se trata de una opción poco habitual, mientras que en el más alto rendimiento es la más frecuente.

También relacionada con el rendimiento encontramos la rotación del equipo en cada momento. La rotación determina la posición de los jugadores en la pista en cada momento del partido, tomándose como referencia la del colocador, y se controla con el orden del saque y las posiciones de los jugadores a lo largo del set (FIVB, 2012), produciéndose una rotación de los jugadores en el sentido de las agujas del reloj en el momento en que el equipo gana un punto en el que había sacado el conjunto rival. Esto hace que en cada rotación la ubicación, funciones y relaciones entre los jugadores sea diferente (Santos, 1992). Tradicionalmente se ha estudiado diferenciando entre rotaciones delanteras y zagueras para el colocador únicamente (Palao, Santos y Ureña, 2002).

Igualmente, parece establecerse una relación entre la finalización de los puntos y los diferentes puestos específicos, especialmente marcada en categorías infantiles, en las que la participación de los jugadores es muy baja (Ureña, Morales, León y González, en prensa), predominando un jugador que finaliza un tercio de las fases de ataque, que no los puntos. Sin embargo, no se encuentra literatura referente al más alto nivel ni a la influencia de los jugadores en la terminación de las jugadas, por lo que como expresaron Häyrinen et al. (2004), parece necesario determinar qué jugadores en sus diferentes funciones guardan una mayor relación con el resultado de los sets y los partidos.

Así, los objetivos de este estudio fueron: (1) comprobar si el número de jugadores que intervienen en las acciones terminales se altera a medida que avanza el set y el partido, (2) determinar si el tipo de acción terminal empleada varía con la progresión del partido, (3) verificar si existe una relación entre el jugador que ejecuta las acciones finales y la rotación del equipo y (4) establecer la relevancia del puesto específico, la rotación y la ubicación en el campo a la hora de la ganar los puntos. 


\section{Método}

\section{Muestra}

Se analizaron 23 partidos correspondientes al Campeonato del Mundo masculino disputado en Italia en 2010, en los que se registraron un total de 5790 acciones finales de 12 selecciones nacionales, distribuidas en 87 sets. Los equipos analizados fueron Alemania, Argentina, Brasil, Bulgaria, Cuba, España, Francia, Italia, República Checa, Rusia, Serbia y Estados Unidos. Para evitar desequilibrios en los resultados, el máximo de partidos analizados para cada selección fue de 4, siendo el mínimo de 3 .

\section{Procedimiento}

El diseño observacional empleado fue nomotético, continuo y multidimensional.

A la hora del registro de acciones que suponen la terminación de los puntos, se tuvo en cuenta únicamente si el jugador llegaba a contactar el balón.

Se utilizaron los criterios y codificación del DATA VOLLEY, universalmente reconocidos en el análisis estadístico de las competiciones de voleibol, que incluye criterios que pueden significar tanto la obtención (acciones terminales positivas, \#) como la pérdida (acciones terminales negativas, $=$ ) del punto.

Los criterios fueron:

- Saque\#: punto directamente obtenido con el servicio, considerándose como tal que el equipo receptor no consiga devolver el balón al campo contrario.

- Saque=: el servicio va directamente fuera o a la red, o el jugador o equipo que saca comete alguna falta reglamentaria que les hace perder el punto.

- Recepción=: el jugador que recibe contacta el balón sin control, finalizando el punto en esta acción a favor del equipo que saca.

- Colocación=: se produce una falta en la ejecución de la misma, como invasión del campo contrario, balón retenido o doble contacto.

- Ataque\#: punto para el equipo que ejecuta el ataque, incluyéndose aquellas acciones en las que la defensa se alarga durante más de un contacto y finalmente no logran devolver el balón al campo del equipo atacante, así como todo contacto del bloqueo rival sin éxito.

- Ataque=: acción de ataque que supone la pérdida del punto, ya sea porque va directamente fuera, a la red, el equipo contrario realiza un bloqueo con éxito o el atacante comete una falta reglamentaria.

- Bloqueo\#: punto directo de bloqueo para el equipo que lo ejecuta. Se incluyen las acciones en las que el balón golpea al atacante de nuevo tras el bloqueo. 
- Bloqueo=: siempre que el balón toca el bloqueo y acaba con punto en contra para el equipo que lo realiza o cualquier falta reglamentaria producida durante esta acción (toque de red, invasión del campo contrario).

- Defensa=: existe uno o más contactos defensivos, sin que finalmente haya transición del balón al campo del equipo que ha atacado.

- Otros: situaciones del juego imposibles de clasificar como alguno de los criterios anteriores, como por ejemplo punto directo con la recepción por engaño del colocador, o cuatro contactos del equipo en una fase del juego por error de interpretación del juego.

Como criterios contextuales se registraron:

- El número de jugada dentro del set y dentro del partido.

- El número de set.

- La rotación de ambos equipos en cada punto.

- El equipo que ejecutó cada acción terminal.

- El puesto específico del jugador que realizó cada acción terminal. Se dividió en dos clasificaciones:

- Clasificación por función: según la posición del jugador en la rotación inicial, independientemente de su ubicación en cada momento (Figura 1):
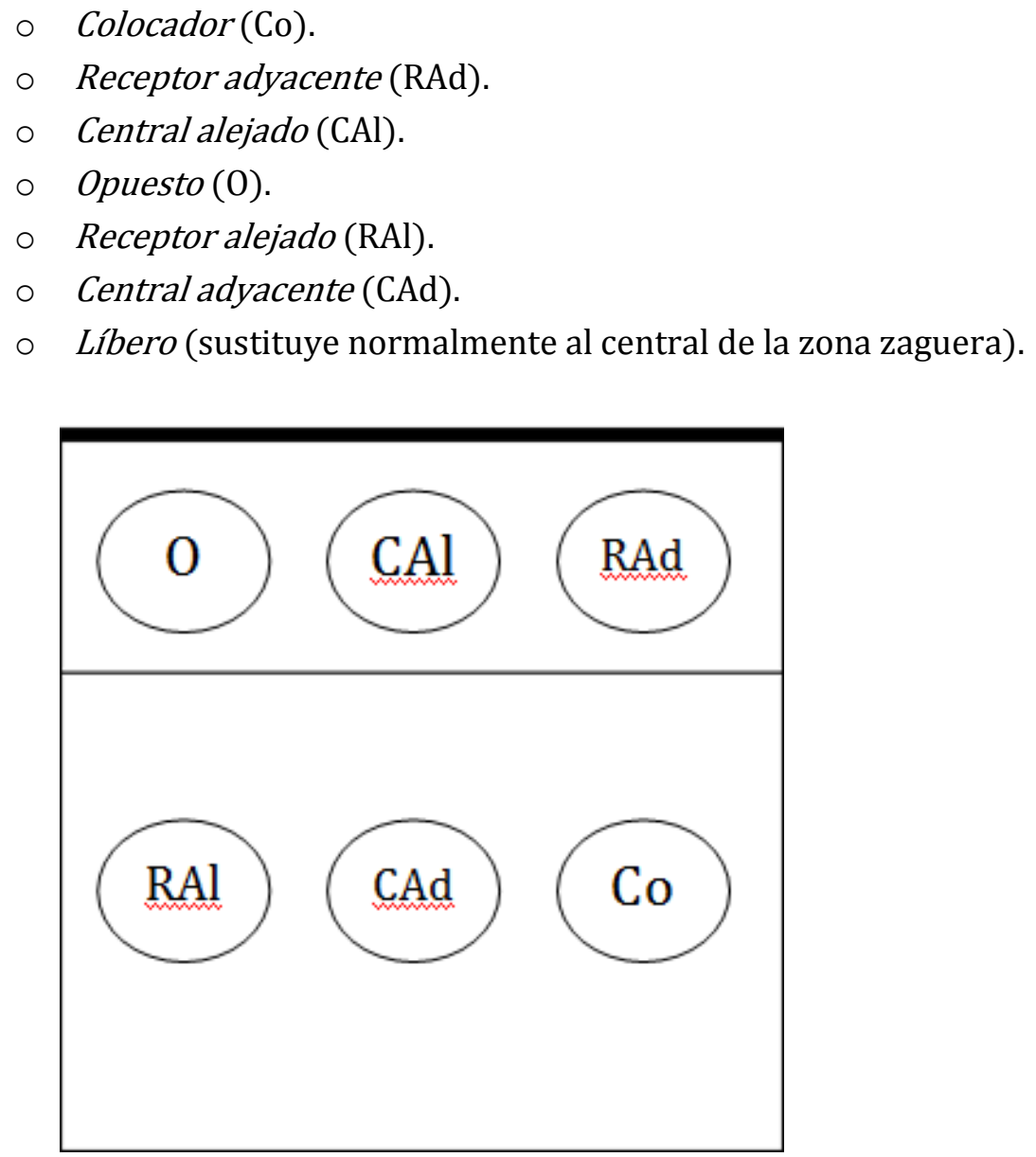

Figura 1. Posición en el campo de los jugadores, clasificados por función. 
- Clasificación por posición: según la posición general del jugador (Figura 2):

- Colocador (Co).

- Receptor(R).

- Central(Ce).

- Opuesto (0).

- Líbero.

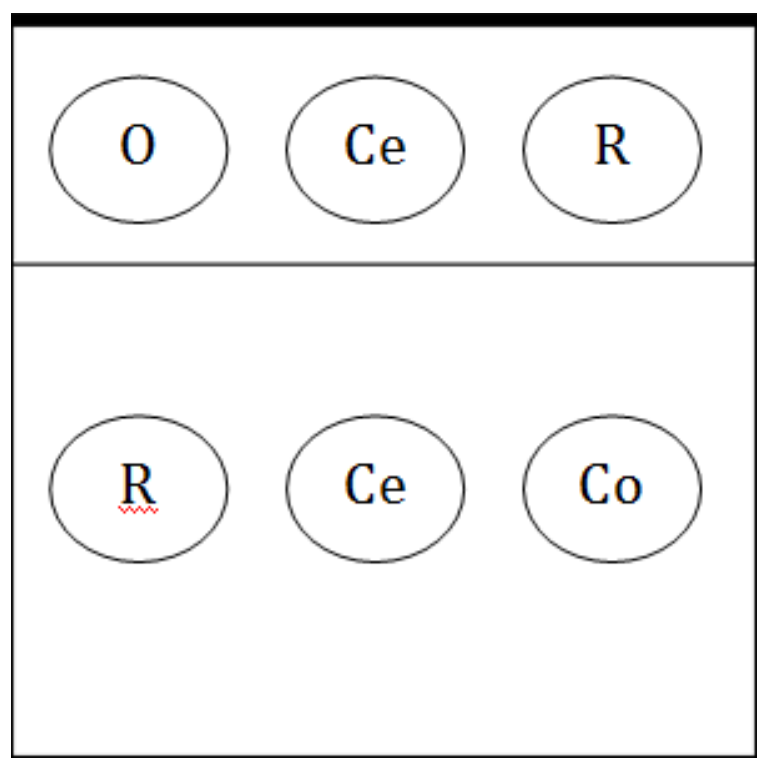

Figura 2. Posición en el campo de los jugadores, clasificados por posición.

Y según su ubicación en el campo en cada momento (Figura 3):

- Zona delantera (zonas 2.3 y 4 ).

- Zona zaguera (zonas 1, 6 y 5).

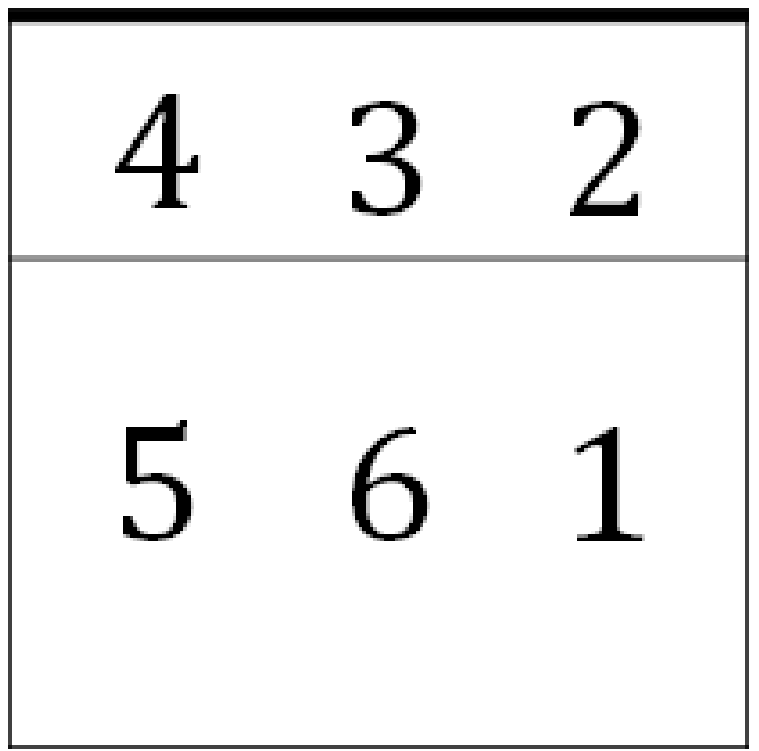

Figura 3. Zona delantera y zaguera del campo de voleibol. 
A la hora de determinar la participación de los jugadores en las acciones finales se tuvieron en cuenta varias opciones:

- Los 87 sets de forma global.

- Los sets 1, 2, 3, 4 y 5 (estos dos últimos, en aquellos partidos que los tuvieran) por separado.

- Los partidos de forma general, contando con que fueran una continuación de puntos no separados en diferentes sets.

Se dividió el total de acciones en 10 grupos, tanto para el análisis de los sets por separado (grupos de 5 jugadas) como para el de los partidos completos (grupos de 18 jugadas).

Asimismo, se separaron las acciones \# de las = por si pudieran existir diferencias.

La grabación de los partidos fue realizada desde una posición superior a la pista, con perfecta visión de la totalidad de ésta, sin modificación de su posición o imagen y sin cortes durante la filmación, evitando así errores de procedimiento.

\section{Instrumento de registro}

Para el registro de los datos se utilizó el software de análisis observacional aplicado al voleibol VA-Sports. El desarrollo de este software se encuadra dentro del proyecto financiado por el Ministerio de Ciencia e Innovación: Sistema MasVb de Evaluación Competitiva y Orientación Técnica para la Superliga Española de Voleibol (DEP201127503), que da marco a este trabajo.

\section{Validez y fiabilidad}

El instrumento de registro empleado aportó la validez necesaria al estudio, a través del sistema de categorías desarrollado, en el que los niveles generados se apoyan en otros autores, pero también incluye otros propios o modificados de los ya existentes. El sistema de categorías fue creado con el objetivo de poder registrar todas las acciones finales posibles con exhaustividad y mutua exclusividad, de manera que todas las conductas posibles se pudieran clasificar sólo en un nivel del mismo.

Para determinar la fiabilidad del sistema de categorías se llevó a cabo un análisis del Kappa de Cohen (1960). Se registró un set aleatorio, con 28 posibles conductas para registrar 57 acciones. La fiabilidad intraobservador fue máxima (1), mientras que la interobservador fue de 0,982, estando ambos valores muy por encima del 0,75 adecuado según Fleiss (2003).

\section{Control de sesgos}

El sesgo de reactividad se puede considerar inexistente dada la alta frecuencia con la que los jugadores de máximo nivel son grabados en sus partidos, tanto por personal externo 
(medios de comunicación) como interno (equipos técnicos con el objetivo de analizar el juego).

La expectancia podría ser una limitación del estudio, al haber actuado como observador el propio investigador. Sin embargo, la exhaustividad del sistema de categorías no da lugar a la interpretación subjetiva de las acciones, como así queda demostrado en los análisis de fiabilidad inter e intraobservador. De esta forma el sesgo de expectancia quedó controlado.

\section{Análisis estadístico}

Para el tratamiento descriptivo de los datos se empleó un estudio de frecuencias y porcentajes.

Para determinar si existía asociación entre los criterios analizados fue necesaria la realización de test Chi-cuadrado de Pearson, considerando como significativos aquellos resultados con $p<0,05$. Las condiciones de validez fueron que no hubiera más del $20 \%$ de los valores esperados por debajo de 5 y que la frecuencia mínima esperada fuera mayor que 1. En aquellos casos en los que estas condiciones de validez no se cumplieran, se llevó a cabo el test Exacto de Fisher.

Cuando se encontraron resultados significativos se analizó la tabla de residuos tipificados y ajustados, tomando aquéllos cuyo valor absoluto se encontrara por encima de 1,96.

Por último, para cuantificar la importancia e influencia de diferentes factores sobre el juego, se llevó a cabo un análisis de regresión logística, que arrojó un modelo que explica la relación entre el resultado de la jugada en función del tipo de jugador, su posición en el campo y la rotación del equipo que realiza la acción. La significación de los coeficientes se contrastó con el test de Wald.

En todos los casos el instrumento estadístico utilizado fue el paquete estadístico SPSS 20 para Windows. 


\section{Resultados}

\section{Intervención de los jugadores en las acciones finales a medida que avanzan los sets de forma general}

En anexos se presenta la tabla de distribución de frecuencias del puesto específico del jugador que realiza la acción cuando el set está en los diez periodos definidos, para la clasificación por función (tabla 1). Se describen más detalladamente en la figura 4, en la que se incluye el porcentaje de acciones finales que ejecuta cada puesto específico, para la clasificación por función.

Los puestos específicos con mayor influencia en las acciones finales fueron el opuesto (26\%) y los receptores, tanto adyacente como alejado (19\% ambos), encontrándose el central alejado (13\%) y adyacente (12\%) con valores similares. En el otro extremo, el colocador (8\%) y el líbero (3\%) fueron los jugadores que menos intervienen en las acciones terminales.

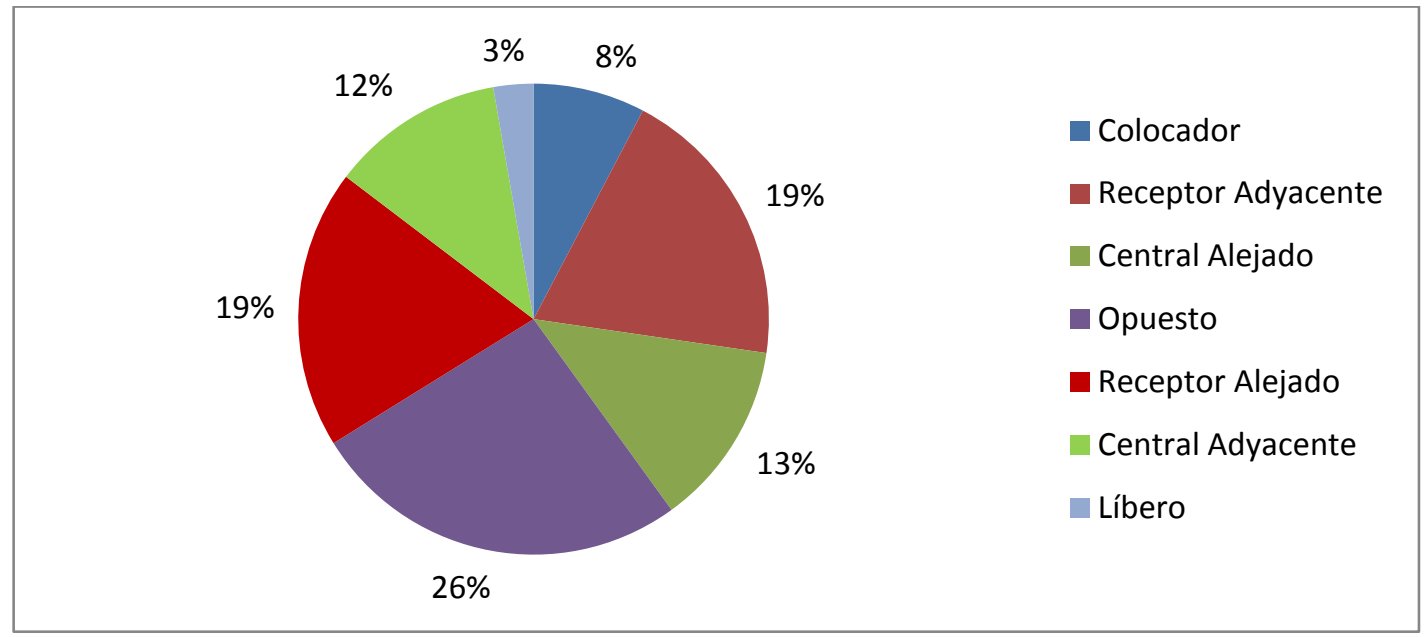

Figura 4. Porcentaje de acciones finales que ejecutó cada puesto específico, para la clasificación por función $(n=5790)$.

El test Chi-cuadrado de Pearson arrojó un resultado de $p<0,10$, por lo que el test fue no significativo, aunque hubo indicios de significación. Por ello, se puede afirmar que no existió asociación entre el desarrollo del set y la participación de jugadores según la clasificación por función, aunque hubo indicios de ello.

En anexos se presenta la tabla de distribución de frecuencias del puesto específico del jugador que realiza la acción cuando el set está en los diez periodos definidos, para la clasificación por posición (tabla 2), las cuales se presentan más adecuadamente en la figura 5, en la que se muestra el porcentaje de acciones terminales en las que interviene cada puesto según la clasificación por posición. 
Los porcentajes de participación del opuesto (26\%), el colocador (8\%) y el líbero (3\%) fueron iguales a los de la figura 4, mientras que los de los receptores (39\%) y los centrales (24\%), al unir 2 jugadores, aumentaron. Sin embargo, éstos últimos no llegaron a superar los del opuesto.

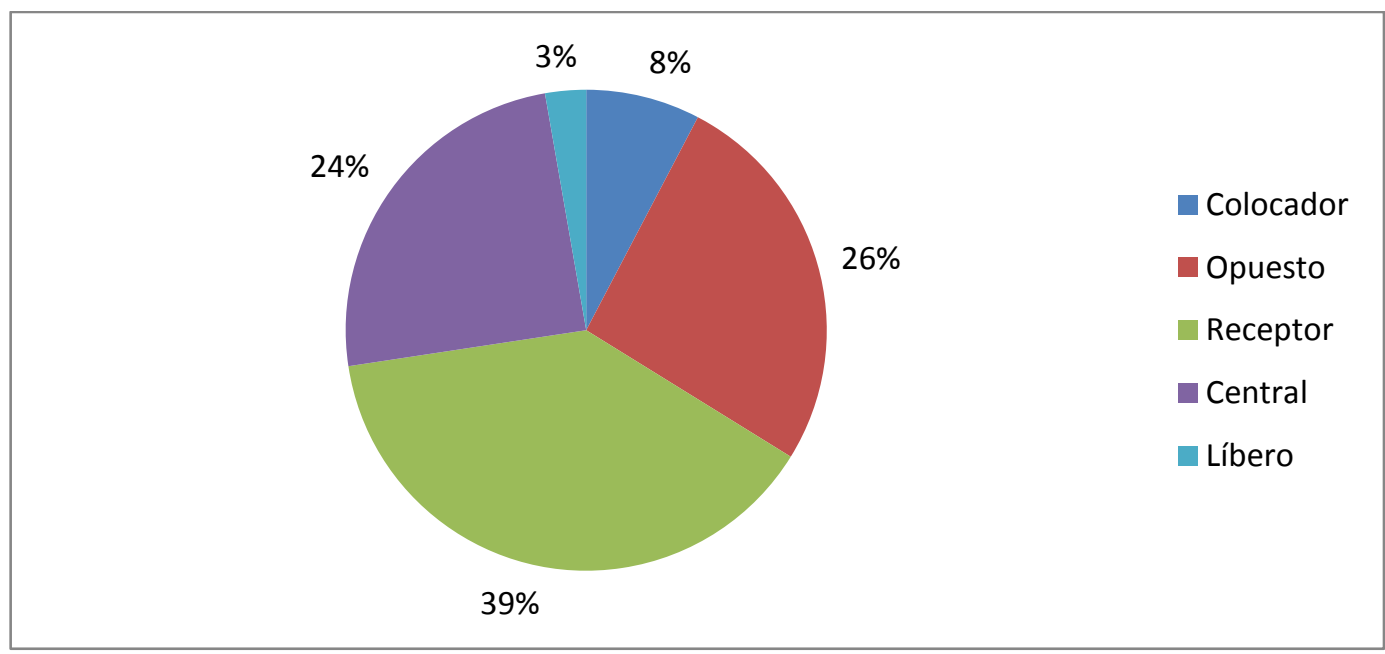

Figura 5. Porcentaje de acciones finales que ejecutó cada puesto específico, para la clasificación por posición $(\mathrm{n}=5790)$.

El test Chi-cuadrado de Pearson fue no significativo, por lo que no existió asociación entre el avance del set, de forma general, y la intervención de los jugadores, clasificados por posición, en las acciones terminales.

\section{Participación de los jugadores en las acciones finales a medida que avanza cada uno de los sets}

Del total de 5790 acciones terminales registradas, 1495 (25,82\%) pertenecieron al primer set, $1546(26,70 \%)$ al segundo, 1619 (27,96\%) tuvieron lugar en el tercero, 972 (16,79\%) en el cuarto y $158(2,73 \%)$ en el quinto y último.

En anexos se incluyen las tablas de distribución de las frecuencias con las que los jugadores, clasificados por función, intervinieron en las acciones terminales en función del periodo del set, teniendo en cuenta cada uno de los sets individualmente (tablas 3-7). Dichas tablas se explican a través de las figuras 6-10, en las que aparece el porcentaje de intervención de cada puesto específico, clasificado por función, teniendo en cuenta cada uno de los sets.

El colocador participó en entre el 7\% y el 9\%; el receptor adyacente se movió entre el 18\% y el 21\%, mientras que el receptor alejado lo hizo entre el 19\% y el 20\%; el opuesto por su parte se situó entre el $23 \%$ y el $27 \%$ en el conjunto de los sets; en cuanto al central alejado, se movió en unos porcentajes entre el 10\% y el 13\%. Estos jugadores mantuvieron relativamente constantes sus porcentajes de intervención en los diferentes sets. Sin 
embargo, el central adyacente, que en los cuatro primeros sets alternó entre el $11 \%$ y el 12\%, en el quinto llegó al 17\% de participación. El líbero también se situó entre el 2\% y el $3 \%$ en los cuatro sets iniciales, mientras que en el último alcanzó el 5\%.

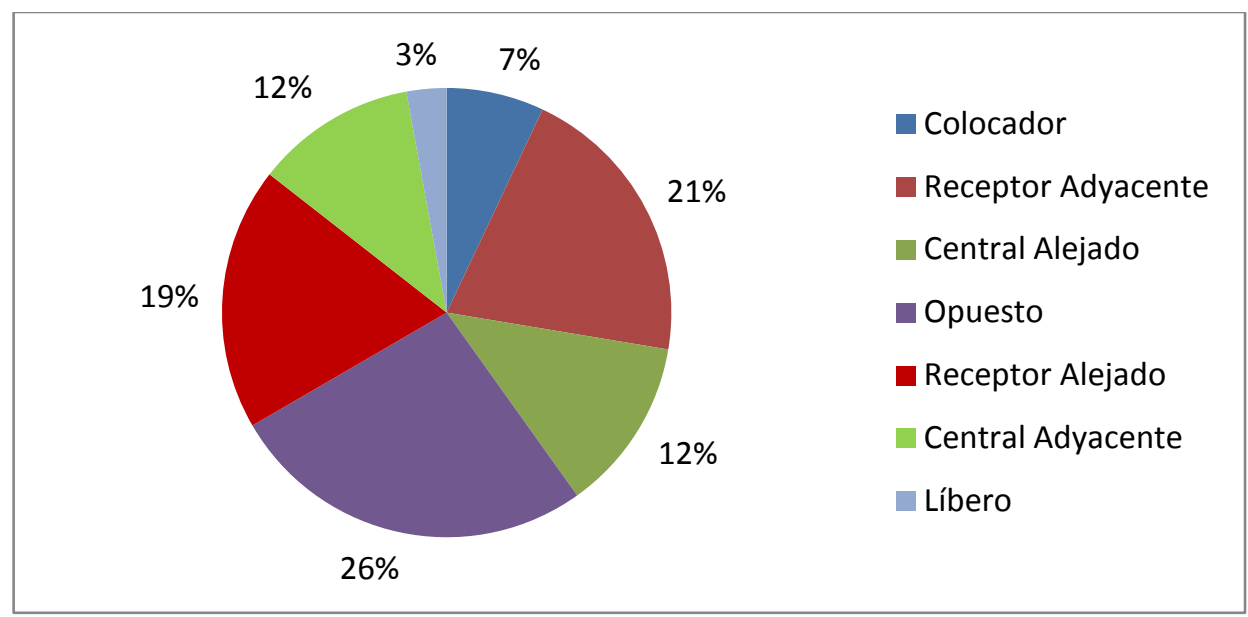

Figura 6. Porcentaje de intervención de cada puesto específico, clasificado por función, en las acciones finales del primer set $(\mathrm{n}=1495)$.

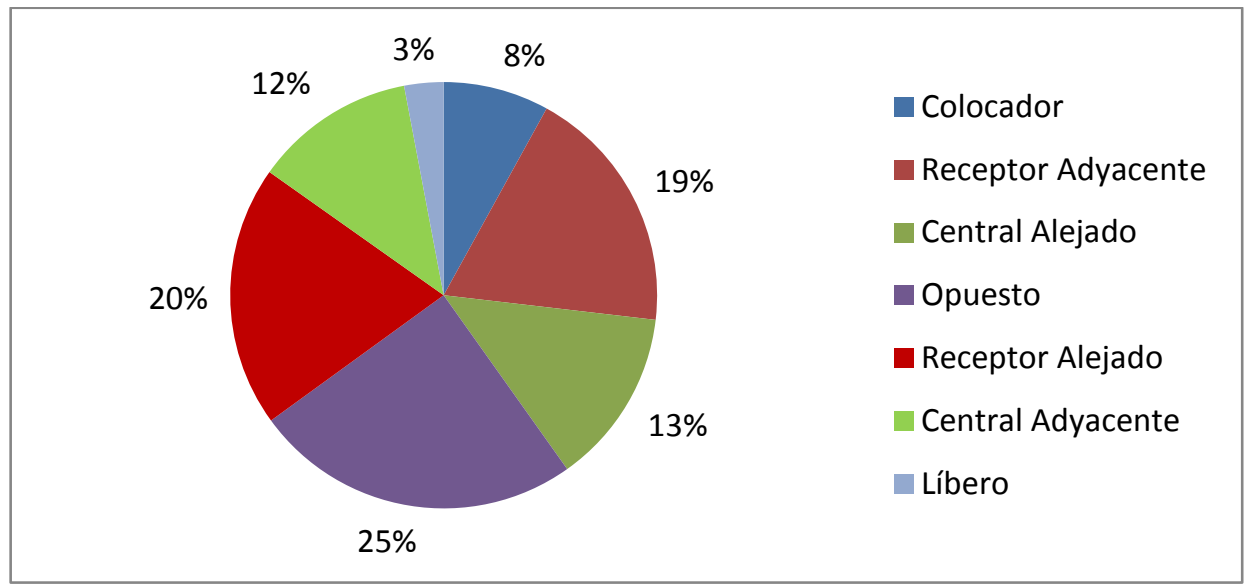

Figura 7. Porcentaje de intervención de cada puesto específico, clasificado por función, en las acciones finales del segundo set $(n=1546)$.

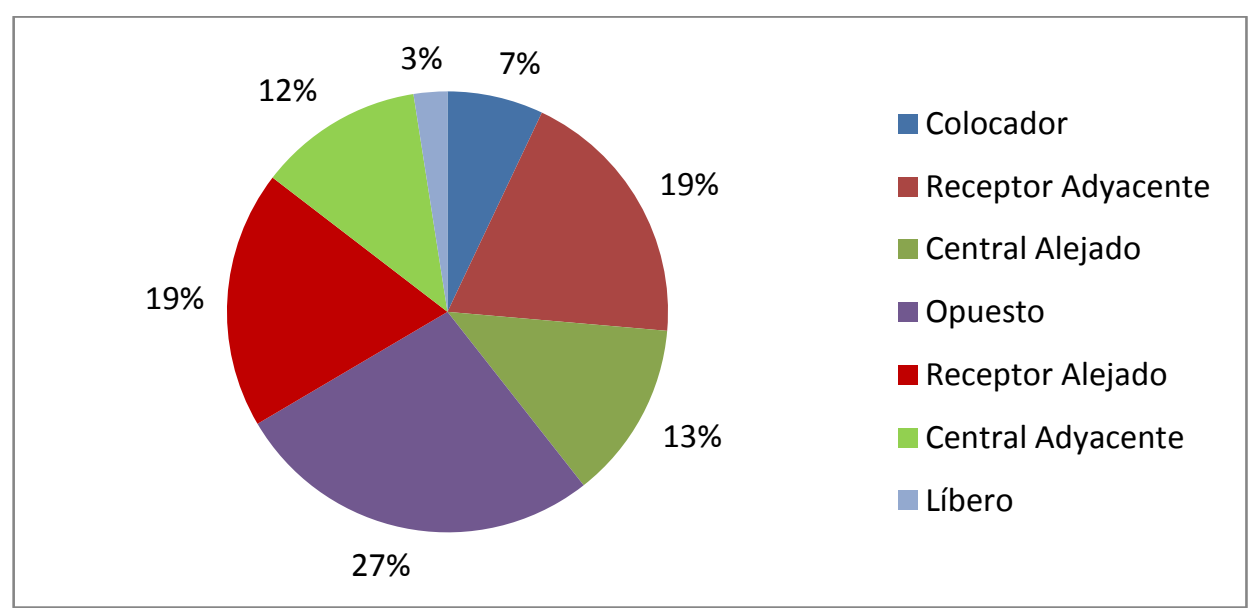

Figura 8. Porcentaje de intervención de cada puesto específico, clasificado por función, en las acciones finales del tercer set $(n=1619)$. 


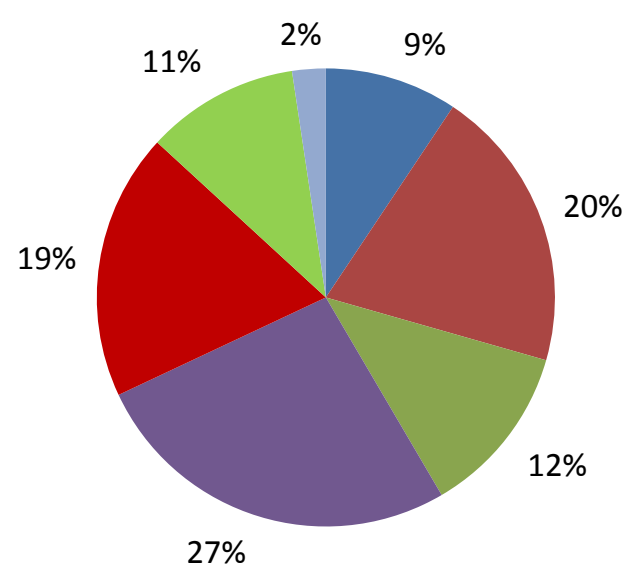

Colocador

Receptor Adyacente

Central Alejado

Opuesto

- Receptor Alejado

Central Adyacente

Líbero

Figura 9. Porcentaje de intervención de cada puesto específico, clasificado por función, en las acciones finales del cuarto set $(n=972)$.

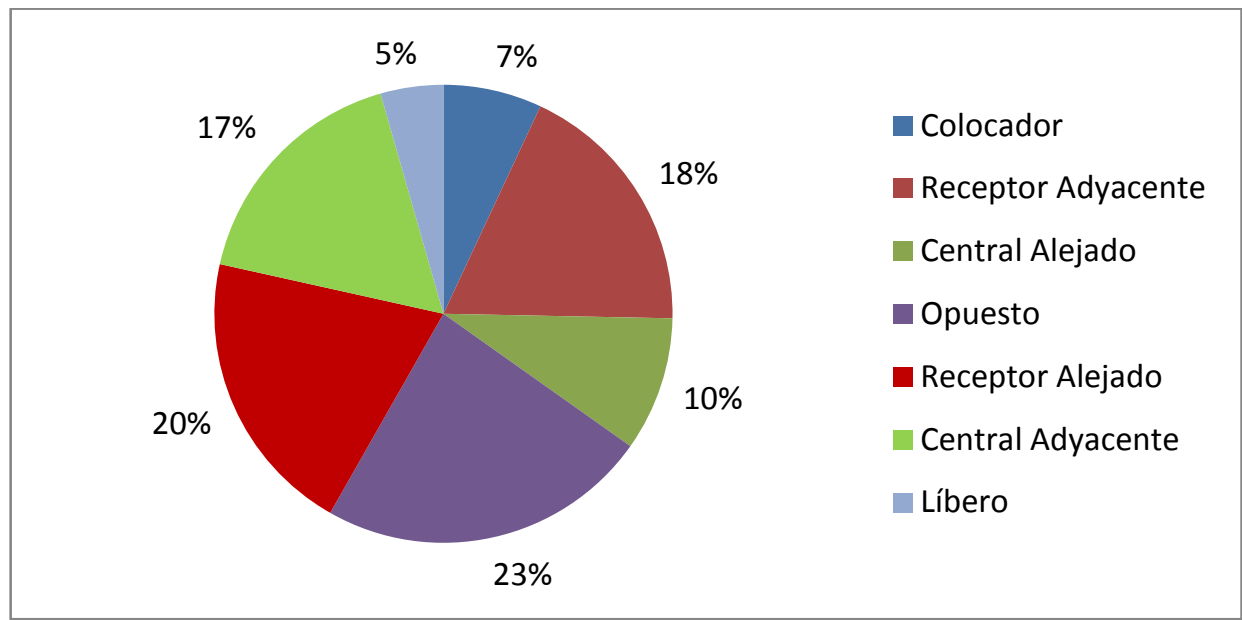

Figura 10. Porcentaje de intervención de cada puesto específico, clasificado por función, en las acciones finales del quinto set $(n=158)$.

Para determinar si existía asociación entre el puesto específico que ejecuta la acción terminal, clasificado por función, y la evolución de cada uno de los sets de forma individual se aplicó el test exacto de Fisher, obteniéndose resultados significativos $(p<0,05)$ únicamente para el primer set.

En la tabla 8 se presentan los residuos estandarizados corregidos para establecer entre qué niveles de los criterios se produjo la asociación entre el jugador que realiza la acción final, clasificado por función, y la evolución del primer set. Se estableció una asociación excitatoria entre el central alejado y el período entre las jugadas 16 y 20, el receptor alejado y las jugadas 26 a 30 y el central adyacente y las jugadas entre la 41 y 45 . Hubo asociación inhibitoria entre el central alejado y el período entre las jugadas 26 y 30. 
Tabla 8. Residuos estandarizados corregidos para la relación entre el jugador que realizó la acción final, clasificado por función, y la evolución del primer set.

\begin{tabular}{ccccccccccc}
\hline & \multicolumn{7}{c}{ Periodo del set } \\
\cline { 2 - 11 } & $\mathbf{1 - 5}$ & $\mathbf{6 - 1 0}$ & $\mathbf{1 1 - 1 5}$ & $\mathbf{1 6 - 2 0}$ & $\mathbf{2 1 - 2 5}$ & $\mathbf{2 6 - 3 0}$ & $\mathbf{3 1 - 3 5}$ & $\mathbf{3 6 - 4 0}$ & $\mathbf{4 1 - 4 5}$ & $>\mathbf{4 5}$ \\
\hline Colocador & $-1,5$ & 1,2 & 1,1 &,- 4 &,- 5 &,- 4 &, 0 &,- 4 &, 5 &, 8 \\
\hline $\begin{array}{c}\text { Receptor } \\
\text { Adyacente }\end{array}$ &, 8 &,- 3 &, 5 &, 0 & $-1,1$ & $-1,7$ & 1,0 & 1,6 &,- 9 &, 2 \\
\hline $\begin{array}{c}\text { Central } \\
\text { Alejado }\end{array}$ &,- 2 & $-1,9$ & 1,6 & $\mathbf{3 , 0}$ &,- 1 & $-\mathbf{2 , 3}$ & 1,1 &,- 3 & $-1,4$ &, 3 \\
\hline $\begin{array}{c}\text { Opuesto } \\
\text { Receptor }\end{array}$ & $-1,3$ &, 9 &,- 8 &, 5 &, 2 &, 6 &, 7 &,- 3 & $-1,0$ &, 8 \\
\hline $\begin{array}{c}\text { Alejado } \\
\text { Central }\end{array}$ & 1,4 &, 7 & $-1,9$ & $-1,3$ & 1,3 & $\mathbf{2 , 2}$ & $-1,7$ & $-1,0$ &, 7 &,- 6 \\
\hline Adyacente & 1,3 & $-1,3$ &, 3 & $-1,2$ &, 6 &, 6 & $-1,2$ &,- 4 & $2,6 *$ & $-1,7$ \\
\hline Líbero & $-1,8$ & 1,1 &, 1 & $-1,3$ &,- 8 & 1,2 &, 0 & 1,2 &, 0 &, 5 \\
\hline
\end{tabular}

* Residuos estandarizados corregidos significativos (su valor absoluto es superior a 1,96).

En el apartado de anexos se incluyen las tablas de distribución de las frecuencias con las que cada puesto específico, clasificados por posición, intervinieron en las acciones terminales en función del periodo del set, teniendo en cuenta cada uno de los sets individualmente (tablas 9-13). Las frecuencias totales de estas tablas se explican a través de las figuras 11-15, en las que aparece el porcentaje de intervención de cada jugador, clasificado por posición, teniendo en cuenta cada uno de los sets.

El colocador, el opuesto y el líbero tuvieron los mismos porcentajes de participación en las acciones finales que con la clasificación con función, ya comentado en las tablas 3-7. Los receptores variaron su intervención a medida que transcurrieron los diferentes sets entre el $38 \%$ y el $40 \%$, mientras que los centrales lo hicieron entre el $23 \%$ y el $27 \%$, por lo que se puede decir que su participación en las acciones terminales se mantuvo constante durante el partido.

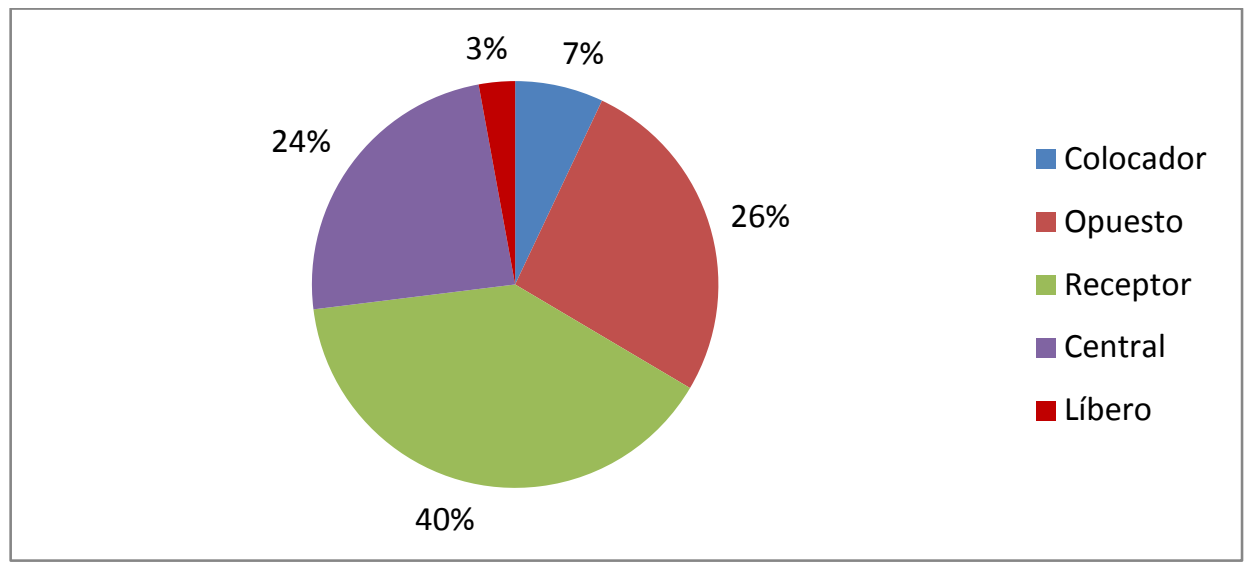

Figura 11. Porcentaje de intervención de cada puesto específico, clasificado por posición, en las acciones finales del primer set $(n=1495)$. 
Análisis de la participación de los jugadores de voleibol masculino de alto nivel mundial en las acciones terminales del juego

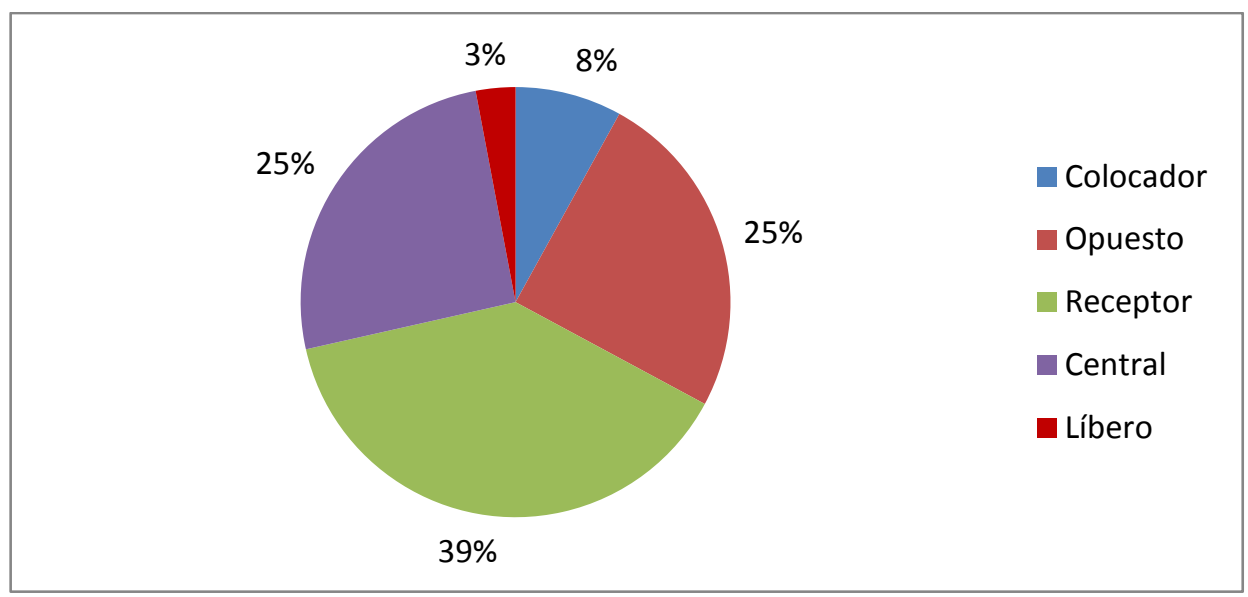

Figura 12. Porcentaje de intervención de cada puesto específico, clasificado por posición, en las acciones finales del segundo set $(n=1546)$.

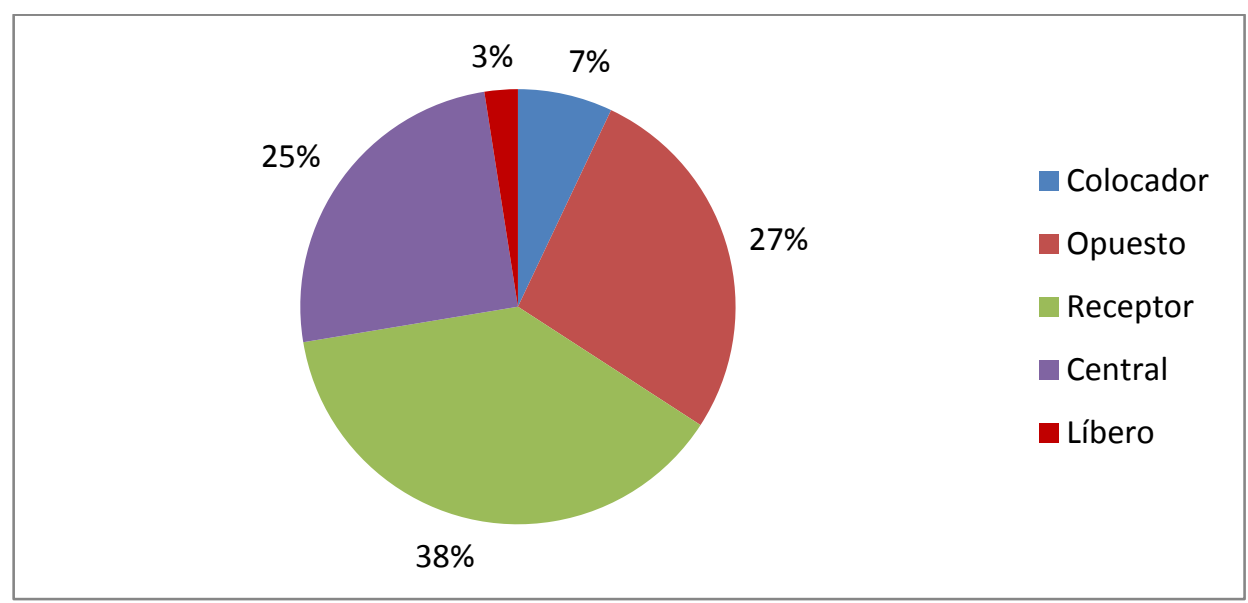

Figura 13. Porcentaje de intervención de cada puesto específico, clasificado por posición, en las acciones finales del tercer set $(n=1619)$.

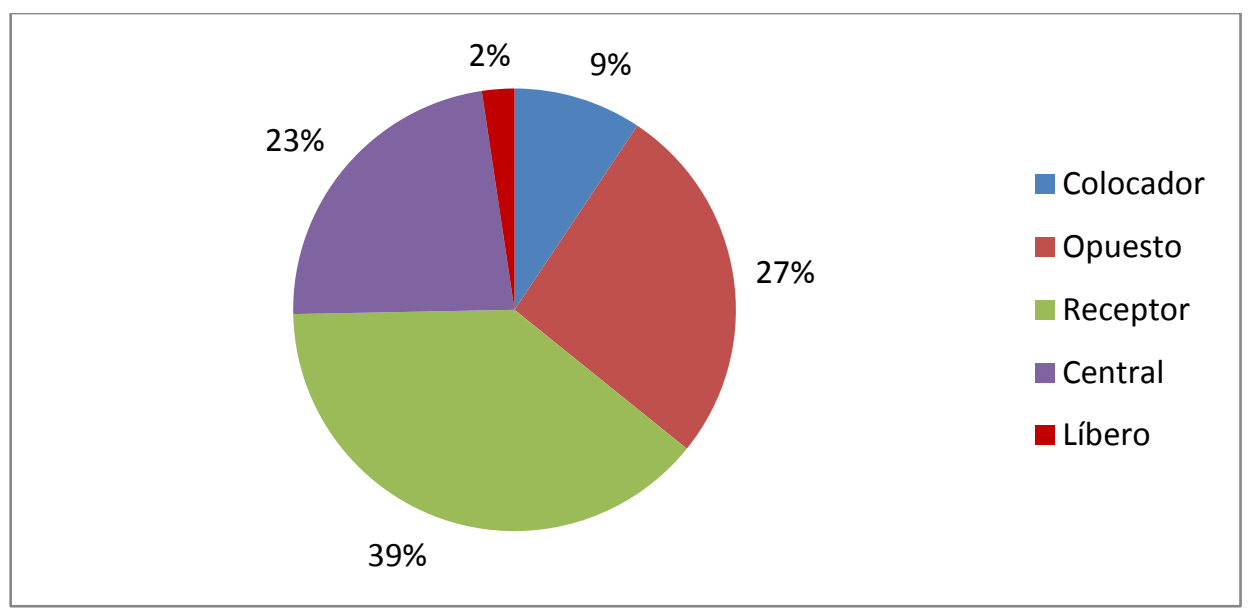

Figura 14. Porcentaje de intervención de cada puesto específico, clasificado por posición, en las acciones finales del cuarto set $(n=972)$. 


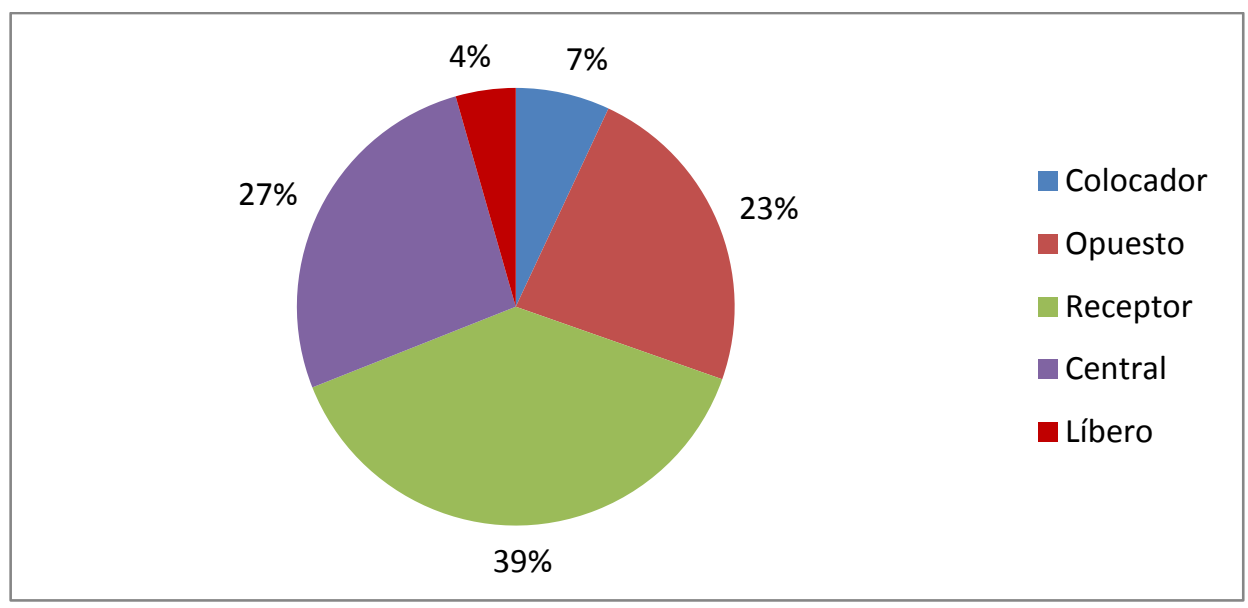

Figura 15. Porcentaje de intervención de cada puesto específico, clasificado por posición, en las acciones finales del quinto set $(n=158)$.

El test exacto de Fisher fue no significativo para todos los casos, por lo que no existió asociación entre los jugadores, clasificados por posición, que realizaron las acciones finales, y el avance de cada uno de los sets por separado.

\section{Intervención de los jugadores en las acciones finales a medida que avanza el partido de forma global}

En anexos se incluye la tabla de distribución de frecuencias que relaciona el puesto del jugador que ejecuta la acción terminal, clasificado por función, en cada uno de los 10 períodos definidos del partido (tabla 14). La figura explicativa de la tabla 14 es idéntica a la figura 4, puesto que incluye las mismas frecuencias totales para la misma clasificación de los jugadores.

El test Chi-cuadrado de Pearson no mostró resultados significativos, por lo que no existió asociación entre el desarrollo del partido y la intervención de los jugadores en las acciones finales, para la clasificación por función.

En cuanto a la clasificación por posición, la tabla de distribución de las frecuencias con que cada puesto específico ejecutó las acciones finales a lo largo de los 10 periodos definidos del partido se incluye en los anexos (tabla 15). La figura resultante de las frecuencias totales de la tabla 15 es igual a la figura 5 , anteriormente detallada.

No se encontró significación al aplicar el test Chi-cuadrado de Pearson, por lo que se puede afirmar que no hay asociación entre la evolución de los partidos y los jugadores que realizaron las acciones terminales, estando estos clasificados por posición. 


\section{Participación de los diferentes jugadores en las acciones terminales positivas a medida que se desarrolla el partido}

De las 5790 acciones terminales registradas, 2860 fueron positivas, es decir, significaron la obtención del punto para el equipo del jugador que la ejecuta, lo cual representó el $49,4 \%$ del total.

En anexos aparece la tabla que muestra las frecuencias con las que cada jugador, clasificado por función, realizó las acciones terminales positivas en cada periodo del partido definido (tabla 16). El líbero, al no poder participar en el ataque, no aparece. La distribución de las frecuencias totales aparece detallada en porcentajes en la figura 16.

El opuesto fue el jugador que más acciones terminales positivas realizó para su equipo (29\%), seguido por los receptores adyacente y alejado (21\% ambos) y con mayor diferencia por el central adyacente (13\%) y alejado (12\%). Por último, el colocador fue el que menos puntos otorgó a su equipo con acciones propias (4\%).

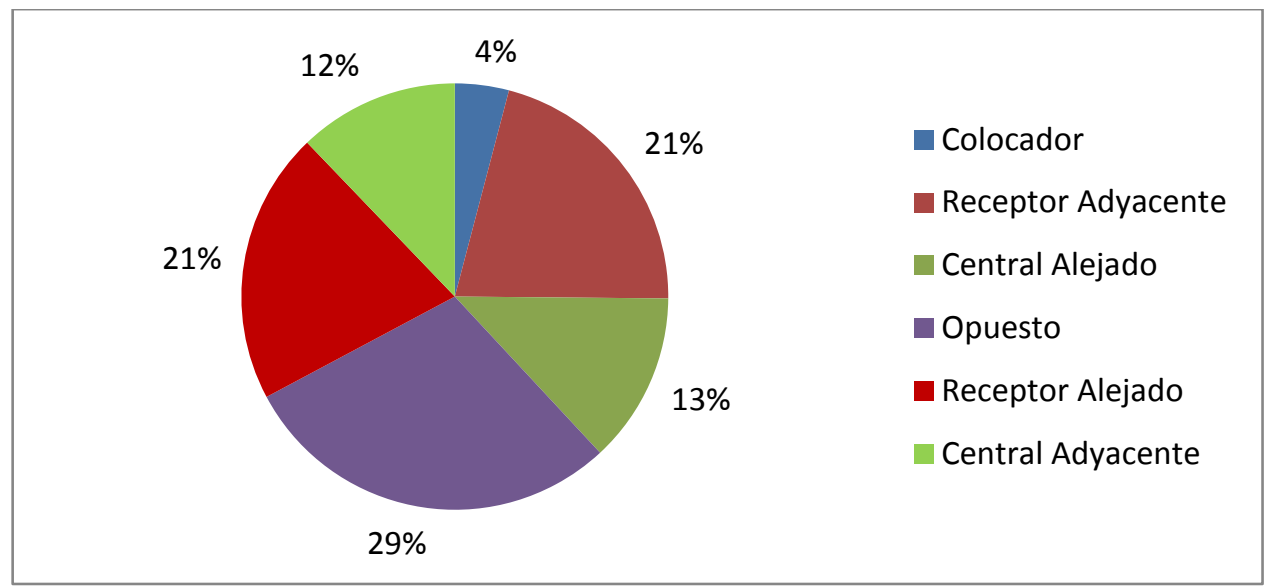

Figura 16. Porcentaje de ejecución de cada puesto específico, clasificado por función, de las acciones terminales positivas $(n=2860)$.

La prueba Chi-cuadrado de Pearson no ofreció resultados significativos, por lo que no existió relación estadística entre el avance del encuentro y la participación de los jugadores, clasificados por función, en las acciones realizadas con éxito.

En cuanto a la clasificación de los jugadores por posición, en anexos se adjunta la tabla de distribución de frecuencias para cada puesto específico, teniendo en cuenta únicamente las acciones terminales positivas a lo largo del partido, segmentado en los 10 periodos definidos (tabla 17). Al tratarse de acciones que significan puntos para el equipo propio, el puesto de líbero no se incluyó. Los porcentajes de las frecuencias totales aparecen en la figura 17. 
En la clasificación por posición los porcentajes de intervención del opuesto y el colocador fueron los mismos que en la clasificación por función (29\% y 4\%, respectivamente). El de receptor, al unir datos de dos jugadores, se convirtió en el puesto específico que más puntos aportó a su equipo con acciones propias (42\% del total), mientras que los jugadores que actuaron como central ejecutaron una de cada cuatro acciones terminales positivas para su equipo (25\%).

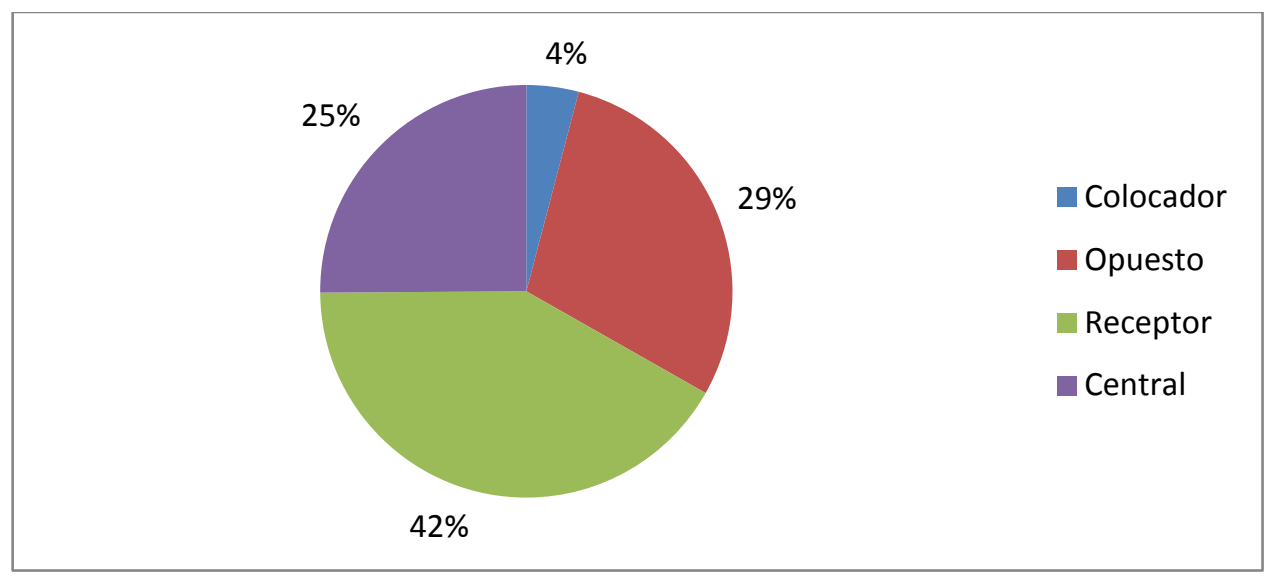

Figura 17. Porcentaje de ejecución de cada puesto específico, clasificado por posición, de las acciones terminales positivas $(n=2860)$.

El test Chi-cuadrado de Pearson no mostró asociación significativa entre el puesto de los jugadores, clasificados por posición, y su participación en las acciones terminales positivas, por lo que no hay relación estadística entre la evolución del partido y la intervención de los jugadores, clasificados por posición, en las acciones finales positivas.

\section{Participación de los diferentes jugadores en las acciones terminales negativas a medida que se desarrolla el partido}

De las 5790 acciones terminales registradas, 2930 fueron negativas, es decir, significaron la pérdida del punto para el equipo del jugador que la ejecutó, lo cual representa el $50,6 \%$ del total.

En anexos aparece la tabla que muestra las frecuencias con las que cada puesto específico, clasificado por función, realizó las acciones terminales negativas en cada periodo del partido definido (tabla 18). Los porcentajes referentes a las frecuencias totales aparecen en la figura 18.

El opuesto, al acumular más intervenciones en total, también fue el que más acciones terminales negativas ejecutó (23\%), seguido una vez más por los receptores adyacente y alejado (18\% cada uno) y los centrales, con valores similares (13\% el adyacente, $12 \%$ el alejado). El colocador participó en el $11 \%$ de las acciones terminales negativas de su equipo, mientras que el líbero lo hizo en el 5\%. 


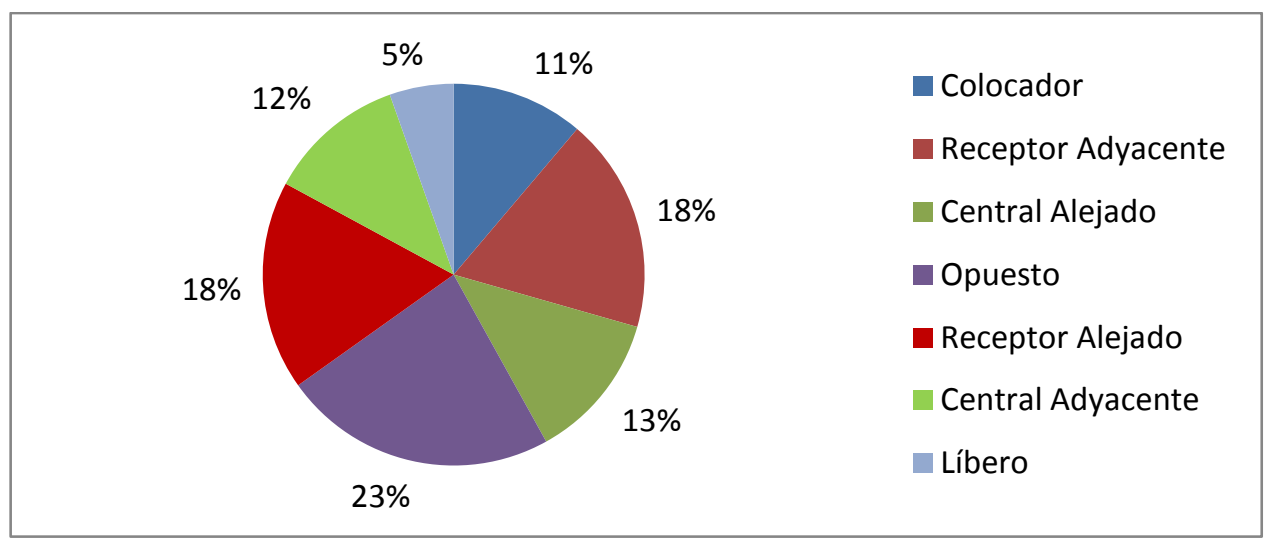

Figura 18. Porcentaje de ejecución de cada puesto específico, clasificado por función, de las acciones terminales negativas $(n=2930)$.

El Chi-cuadrado de Pearson no ofreció resultados significativos, por lo que no hay asociación entre el desarrollo del partido y la ejecución de los jugadores, clasificados por función, en las acciones terminales positivas.

En lo que respecta a la clasificación de los jugadores por posición, en la tabla 19 (anexos) se presenta la distribución de frecuencias según las acciones terminales negativas que ejecuta cada puesto específico en cada periodo del partido. En la figura 19 aparecen los porcentajes de ejecución de las acciones terminales negativas por puesto específico, clasificados por posición.

El opuesto (23\%), el colocador (11\%) y el líbero (5\%) una vez más, en la clasificación por posición y por función cuentan con las mismas frecuencias. Los receptores suman más de un tercio de las acciones terminales negativas para su equipo (36\%), mientras que los centrales ejecutan el mismo porcentaje que de acciones terminales positivas (25\%).

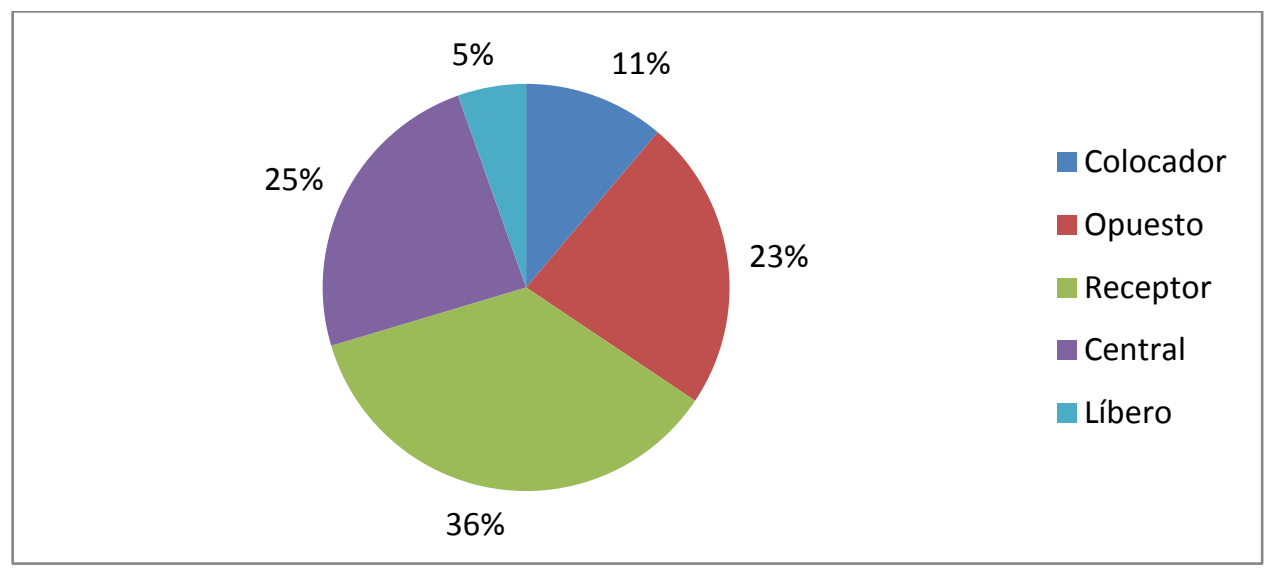

Figura 19. Porcentaje de ejecución de cada puesto específico, clasificado por posición, de las acciones terminales negativas $(n=2930)$.

El análisis Chi-cuadrado de Pearson llevado a cabo no mostró resultados significativos, por lo que no existe asociación entre el desarrollo del partido y la intervención de los jugadores, clasificados por posición, en las acciones terminales negativas. 


\section{Acciones terminales a medida que avanza el partido}

La tabla de distribución de frecuencias para las acciones terminales que tienen lugar en cada periodo del partido se presenta en el apartado de anexos (tabla 20). Para explicar las frecuencias totales se utilizan porcentajes, presentados en la figura 20.

La acción más habitual a la hora de finalizar un punto es el ataque con éxito (39\%). A distancia le siguen el ataque fallado (14\%), el bloqueo error (13\%), el fallo en el saque (11\%) y el error en la defensa (10\%). En el otro extremo encontramos los errores en la colocación (1\%) y recepción (2\%) y el punto directo con el servicio (3\%), además de las acciones catalogadas como otros, que representan una parte mínima (0\%), como se puede ver en la tabla 20.

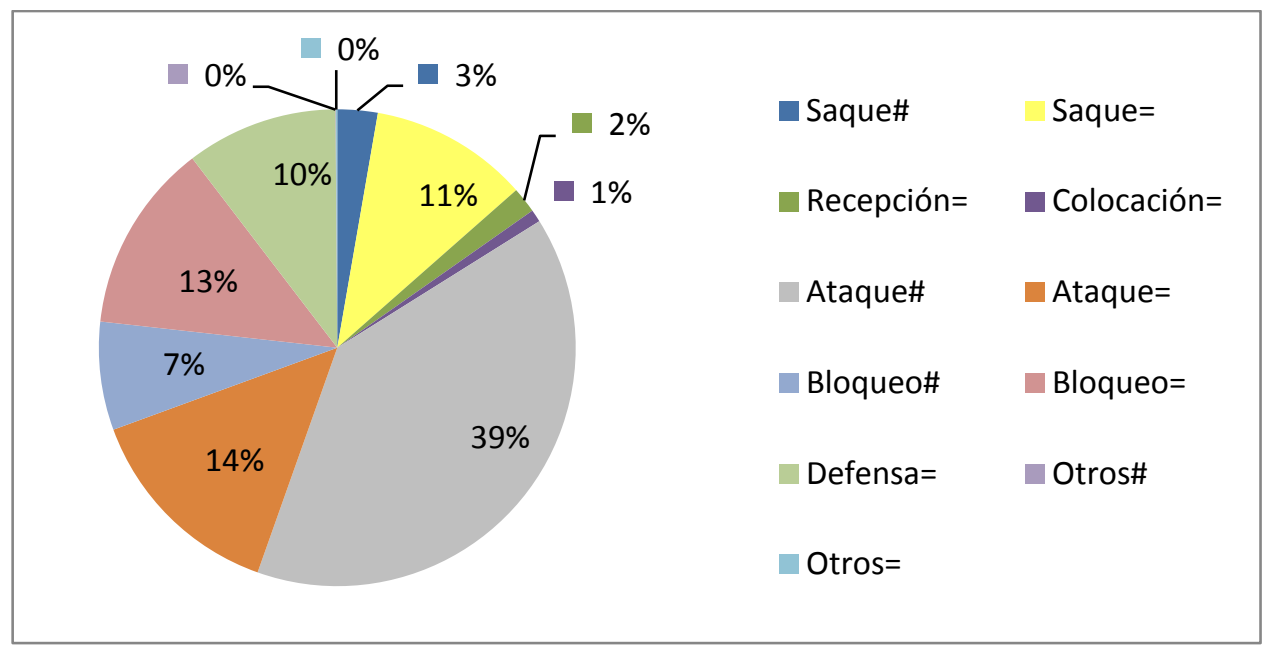

Figura 20. Porcentaje en que tiene lugar cada acción terminal $(n=5790)$.

Para analizar si existió asociación entre la ejecución de las acciones finales y el periodo del encuentro se aplicó un test exacto de Fisher, sin encontrarse efectos significativos, por lo que en cualquier caso la proporción con la que se dan las diferentes acciones para la obtención o pérdida de puntos se mantiene constante a lo largo del juego..

\section{Relación entre el jugador que ejecuta la acción terminal y la rotación}

En la tabla 21 se presentan las frecuencias con las que cada jugador, clasificado por función, ejecutó la acción terminal, en función de la rotación de su equipo en cada momento. 
Tabla 21. Frecuencias con las que cada puesto específico, clasificado por función, realizó la acción terminal según la rotación del equipo.

\begin{tabular}{|c|c|c|c|c|c|c|c|}
\hline & \multicolumn{6}{|c|}{ Rotación } & \multirow{2}{*}{ Total } \\
\hline & 1 & 2 & 3 & 4 & 5 & 6 & \\
\hline Colocador & 129 & 88 & 59 & 83 & 48 & 38 & 445 \\
\hline Receptor adyacente & 267 & 233 & 240 & 78 & 77 & 241 & 1136 \\
\hline Central alejado & 207 & 189 & 1 & 0 & 149 & 191 & 737 \\
\hline Opuesto & 246 & 175 & 198 & 398 & 259 & 237 & 1513 \\
\hline Receptor alejado & 88 & 63 & 169 & 252 & 254 & 284 & 1110 \\
\hline Central adyacente & 0 & 134 & 173 & 188 & 195 & 0 & 690 \\
\hline Líbero & 40 & 4 & 32 & 31 & 11 & 41 & 159 \\
\hline Total & 977 & 886 & 872 & 1030 & 993 & 1032 & 5790 \\
\hline
\end{tabular}

Para analizar cada puesto específico individualmente, se incluye la figura 21. Se observa que los receptores y los centrales, tanto adyacentes como alejados, tuvieron mayor participación en aquellas rotaciones en las que se encontraban en zona delantera (receptor adyacente: 1,2 y 3; central alejado: 1,2 y 6; receptor alejado: 4,5 y 6; y central adyacente: 3,4 y 5), seguidas por la rotación en la que debían sacar (receptor adyacente: 6 ; central alejado: 5; receptor alejado: 3; y central adyacente: 2). En el caso del opuesto, al tratarse de un jugador que se suele utilizar en ataque (la acción terminal más habitual) independientemente de que se encontrara en zona delantera o zaguera, su participación en todas las rotaciones se equilibró con la excepción de la rotación 4, en la que tiene que sacar; en ella realiza una de cada cuatro acciones terminales. El colocador por su parte acumuló gran cantidad de acciones en rotación 1, en la que tiene que sacar, seguidas por sus rotaciones delanteras (1, 2 y 3 ). En cuanto al líbero, las restricciones normativas a las que se ve sometido hacen que únicamente pueda jugar en posiciones zagueras, normalmente sustituyendo al central que se encuentra en dicha posición, con la excepción de las jugadas en las que el central tiene que servir, es decir, en las rotaciones 2 y 5 .

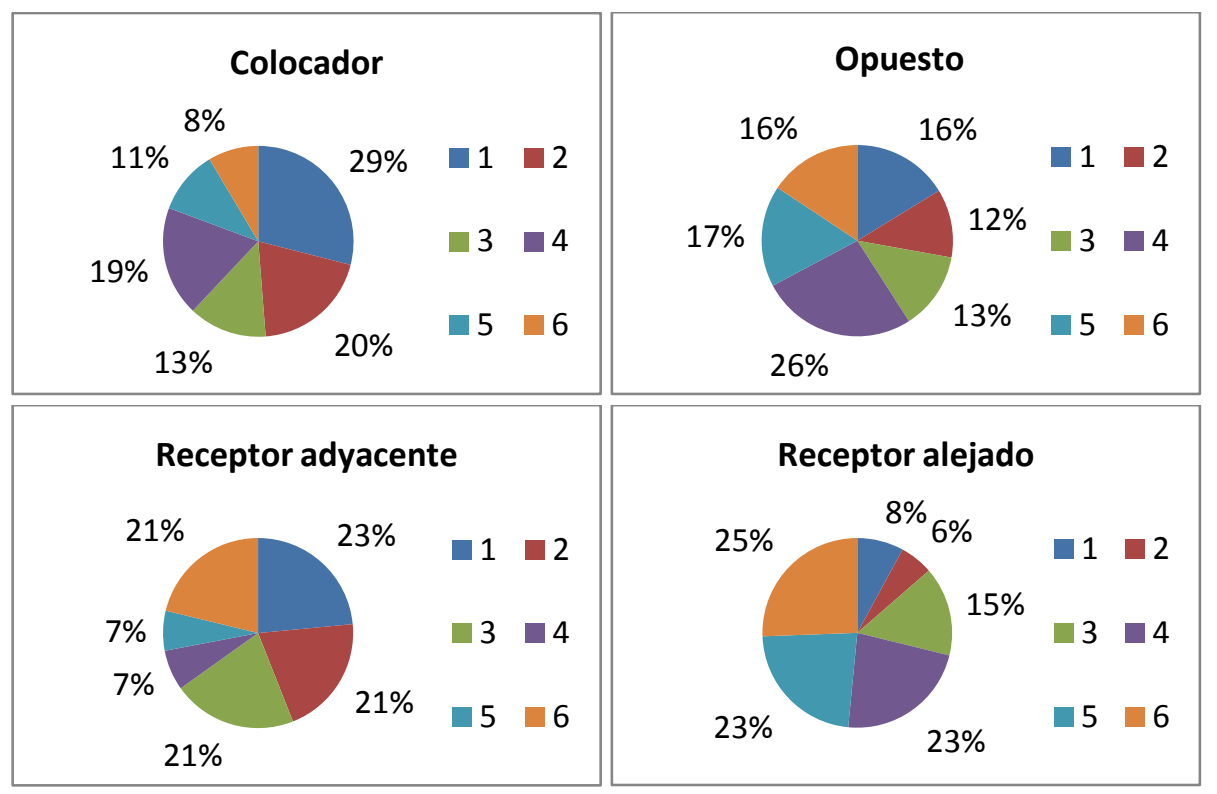




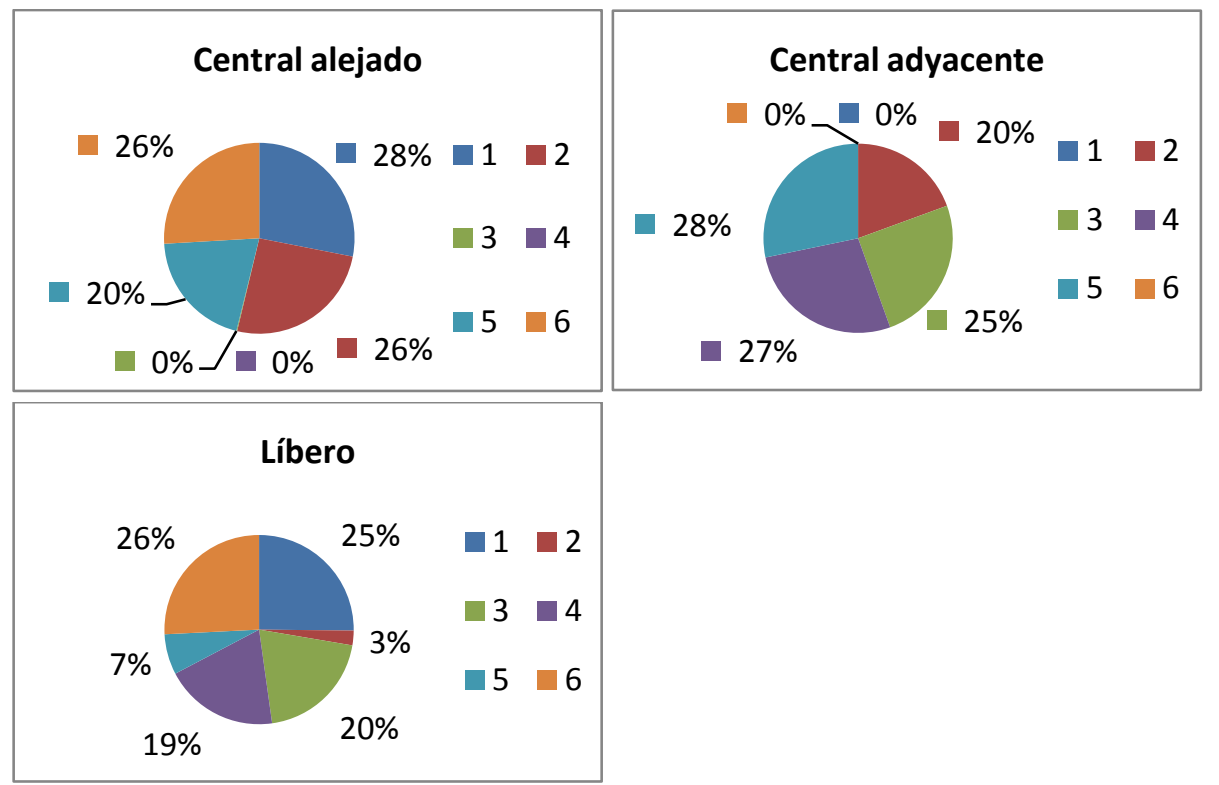

Figura 21. Porcentaje de intervención en las acciones terminales de cada puesto específico, clasificado por función, según la rotación.

El test Chi-cuadrado de Pearson mostró una asociación altamente significativa $(p<0,001)$, por lo que existió relación estadística entre la rotación del equipo y el puesto específico, clasificado por función, que ejecutó la acción terminal.

En la tabla 22 aparecen los residuos estandarizados corregidos. Se estableció una relación excitatoria entre el colocador y las rotaciones 1 y 2 , el receptor adyacente y las rotaciones 1, 2, 3 y 6, el central alejado y las rotaciones 1, 2, 5 y 6, el opuesto y la rotación 4, el receptor alejado y las rotaciones 4, 5 y 6, el central adyacente y las rotaciones 2, 3, 4 y 5 y el líbero y las rotaciones 1 y 6 , siendo inhibitoria para el colocador en las rotaciones 5 y 6 , para el receptor adyacente en las rotaciones 4 y 5 , para el central alejado en las rotaciones 3 y 4, para el opuesto en las rotaciones 2, 3 y 6, para el receptor alejado en las rotaciones 1 y 2 , para el central adyacente en las rotaciones 1 y 6 y para el líbero en las rotaciones 2 y 5.

Tabla 22. Residuos estandarizados corregidos para los puestos específicos, clasificados por función, según la rotación del equipo que ejecutó la acción terminal.

\begin{tabular}{ccccccc}
\hline & \multicolumn{7}{c}{ Rotación } \\
\cline { 2 - 7 } & 1 & 2 & 3 & 4 & 5 & 6 \\
\hline Colocador & $7,1^{*}$ & $2,7^{*}$ & $-1,1$ &, 5 & $-3,7^{*}$ & $-5,3^{*}$ \\
\hline Receptor adyacente & $6,7^{*}$ & $5,4^{*}$ & $6,4^{*}$ & $-10,7^{*}$ & $-10,3^{*}$ & $3,3^{*}$ \\
\hline Central alejado & $8,7^{*}$ & $8,3^{*}$ & $-12,1^{*}$ & $-13,5^{*}$ & $2,4^{*}$ & $6,1^{*}$ \\
\hline Opuesto &,- 7 & $-4,7^{*}$ & $-2,5^{*}$ & $10,1^{*}$ &, 0 & $-2,6^{*}$ \\
\hline Receptor alejado & $-8,9^{*}$ & $-9,9^{*}$ &, 2 & $4,8^{*}$ & $5,6^{*}$ & $7,5^{*}$ \\
\hline Central adyacente & $-12,6^{*}$ & $3,2^{*}$ & $7,8^{*}$ & $6,9^{*}$ & $8,2^{*}$ & $-13,0^{*}$ \\
\hline Líbero & $2,8^{*}$ & $-4,5^{*}$ & 1,8 &, 6 & $-3,5^{*}$ & $2,7^{*}$ \\
\hline
\end{tabular}

* Residuos estandarizados corregidos significativos (su valor absoluto es superior a 1,96). 
A continuación se presenta la tabla 23, que incluye la distribución de frecuencias del puesto específico que ejecutó la acción terminal, clasificado por posición, en función de la rotación del equipo.

Tabla 23. Frecuencias con las que cada puesto específico, clasificado por posición, realizó la acción terminal en función de la rotación del equipo.

\begin{tabular}{cccccccc}
\hline & \multicolumn{9}{c}{ Rotación } & Total \\
\cline { 2 - 7 } & $\mathbf{1}$ & $\mathbf{2}$ & $\mathbf{3}$ & $\mathbf{4}$ & $\mathbf{5}$ & $\mathbf{6}$ & \\
\hline Colocador & 129 & 88 & 59 & 83 & 48 & 38 & 445 \\
\hline Opuesto & 246 & 175 & 198 & 398 & 259 & 237 & 1513 \\
\hline Receptor & 355 & 296 & 409 & 330 & 331 & 525 & 2246 \\
\hline Central & 207 & 323 & 174 & 188 & 344 & 191 & 1427 \\
\hline Líbero & 40 & 4 & 32 & 31 & 11 & 41 & 159 \\
\hline Total & 977 & 886 & 872 & 1030 & 993 & 1032 & 5790 \\
\hline
\end{tabular}

En la figura 22 se presentan los porcentajes de participación de cada puesto específico, clasificado por posición, en función de la rotación. En los puestos de centraly receptor, al reunir datos de dos jugadores en esta segunda clasificación, se equilibró la participación en el conjunto de las rotaciones, con la excepción de aquéllas en las que deben sacar (receptores: 3 y 6; centrales: 2 y 5). En el caso del colocador, el opuesto y el líbero, los resultados fueron iguales a los mostrados en la figura 21.

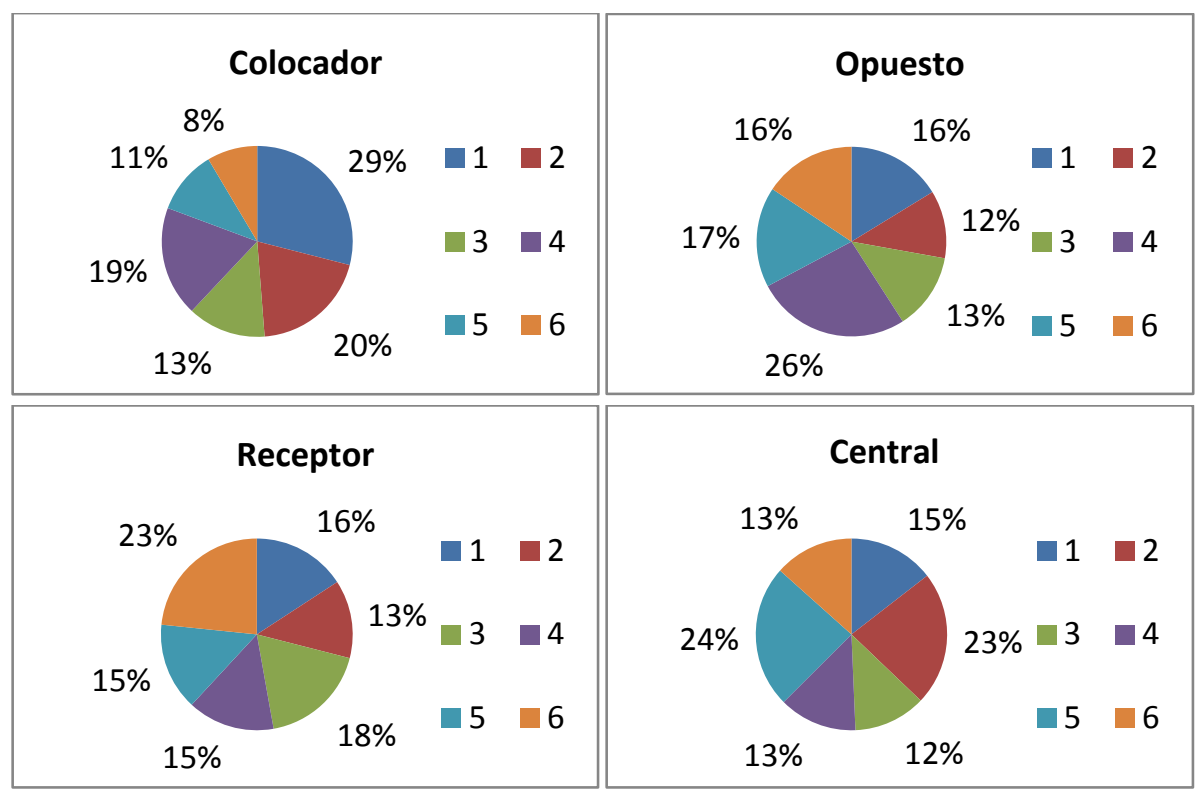




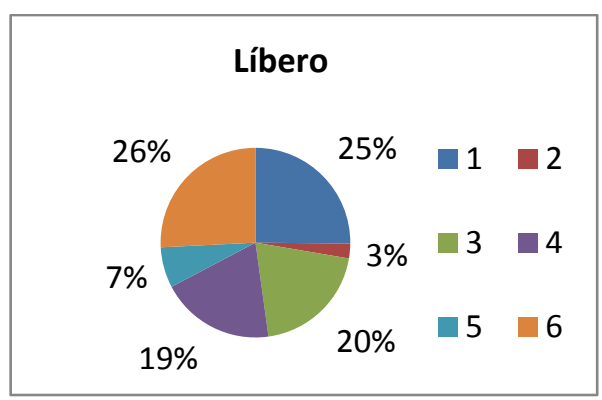

Figura 22. Porcentaje de intervención en las acciones terminales de cada puesto específico, clasificado por posición, según la rotación.

El test Chi-cuadrado de Pearson mostró una asociación altamente significativa $(p<0,001)$, por lo que se encontró relación estadística entre la rotación del equipo y el puesto específico, clasificado por posición, que ejecutó la acción terminal.

En la tabla 24 se ofrecen los residuos estandarizados corregidos para esta relación. Hubo asociación excitatoria entre los puestos específicos de colocador y las rotaciones 1 y 2 , opuesto y rotación 4, receptor y rotaciones 3 y 6 , central y rotaciones 2 y 5 y líbero y rotaciones 1 y 6 . En cuanto a la asociación inhibitoria, se produjo entre el colocador y las rotaciones 5 y 6 , el opuesto y las rotaciones 2,3 y 6, el receptory las rotaciones 2 , 4 y 5 , el centraly las rotaciones 1, 2, 3 y 6 y el líbero y las rotaciones 2 y 5 .

Tabla 24. Residuos estandarizados corregidos para los puestos específicos, clasificados por posición, según la rotación del equipo que ejecutó la acción terminal.

\begin{tabular}{ccccccc}
\hline & \multicolumn{7}{c}{ Rotación } \\
\cline { 2 - 7 } & 1 & 2 & 3 & 4 & 5 & 6 \\
\hline Colocador & $7,1^{*}$ & $2,7^{*}$ & $-1,1$ &, 5 & $-3,7^{*}$ & $-5,3^{*}$ \\
\hline Opuesto &,- 7 & $-4,7^{*}$ & $-2,5^{*}$ & $10,1^{*}$ &, 0 & $-2,6^{*}$ \\
\hline Receptor & $-1,7$ & $-3,6^{*}$ & $5,3^{*}$ & $-4,9^{*}$ & $-3,9^{*}$ & $8,8^{*}$ \\
\hline Central & $-2,8^{*}$ & $8^{*} 9^{*}$ & $-3,5^{*}$ & $-5,3^{*}$ & $8,0^{*}$ & $-5,0^{*}$ \\
\hline Líbero & $2,8^{*}$ & $-4,5^{*}$ & 1,8 &, 6 & $-3,5^{*}$ & $2,7^{*}$ \\
\hline
\end{tabular}

* Residuos estandarizados corregidos significativos (su valor absoluto es superior a 1,96).

\section{Factores que afectan a la probabilidad de ganar el punto}

La regresión logística ofreció un modelo (tabla 25) que muestra la probabilidad de ganar las jugadas en función del puesto específico del jugador, clasificado por posición y tomando como referencia al opuesto, la rotación del equipo que realiza la acción y la ubicación en el campo (zona delantera respecto a zona zaguera).

A excepción de la rotación todos los criterios fueron altamente significativos para el modelo $(p<0,001)$. 
Así, en relación con el opuesto, la odds ratio o razón de ventajas (OR) del colocador fue de 0,25 , es decir, es 4 veces menos probable que el colocador realice la acción terminal con éxito. El receptor por su parte tuvo una OR de 0,723 , por lo que la probabilidad de que finalice las jugadas con éxito, comparado con el opuesto, es de 1,38 veces menor aproximadamente. Por último, el central obtuvo una OR de 0,553 , lo cual significa que la probabilidad de que ejecute la acción terminal con resultado de punto para su equipo es 1,81 veces menor aproximadamente que si fuera opuesto.

En cuanto a la ubicación del jugador que realizó la acción terminal con éxito, la OR de la zona delantera fue de 3,271 , por lo que la probabilidad de que un jugador, cualquiera que sea, en zona delantera gane la jugada para su equipo es 3,27 veces mayor que si ejecutara dicha acción desde zona zaguera.

Tabla 25. OR e IC de los diferentes puestos específicos, la rotación y la ubicación en el campo.

\begin{tabular}{cc} 
& OR (IC del 95\% para OR) \\
\hline Jugador & \\
\hline Colocador** $^{* *}$ & $0,250^{*}(0,196 ; 0,319)$ \\
\hline Receptor* $^{* *}$ & $0,723^{*}(0,629 ; 0,831)$ \\
\hline Central $^{* *}$ & $0,553^{*}(0,473 ; 0,647)$ \\
\hline Rotación & $0,974(0,943 ; 1,007)$ \\
\hline Zona delantera*** & $3,271^{*}(2,897 ; 3,692)$ \\
\hline
\end{tabular}

$\mathrm{OR}=$ odds ratio IC $=$ intervalo de confianza.

$* p<0,001$

** Respecto al jugador opuesto.

*** Respecto a la zona zaguera. 


\section{Discusión}

Se realizaron análisis para comprobar la asociación del puesto específico, en sus dos clasificaciones, que ejecuta la acción terminal con el desarrollo del partido, en todas sus variantes, a saber, a medida que avanza el set de forma general e individual y a medida que avanza el partido de forma global, tanto para acciones terminales en su conjunto, como positivas y negativas por separado. La evolución del set no altera significativamente el jugador que participa, por lo que no parece que en este nivel haya un desequilibrio en los finales de set en beneficio de los potenciales jugadores estelares. Del mismo modo sucede a lo largo de los diferentes sets. Se produce una excepción en la fase intermedia del primer set, aunque no encontramos explicación o trascendencia a esta circunstancia, bastante aislada por otra parte.

La falta de significación en la mayoría de los análisis llevados a cabo, teniendo en cuenta diferentes criterios, da muestra del equilibrio de los conjuntos que disputaron el campeonato, y es que como afirman Häyrinen et al. (2004) en estos niveles de rendimiento los resultados entre equipos tienden a estar muy igualados. Esta ausencia de resultados significativos refleja la regularidad con la que los equipos de máximo nivel son capaces de desarrollar su juego a lo largo de los partidos, al no verse reducida la intervención de sus diferentes jugadores a medida que avanzan los mismos. Así, los equipos rivales no pueden encontrar patrones de juego que les permitan anticipar de una u otra forma sus movimientos. Podemos decir que sólo a medida que avanza el primer set los equipos alteran la participación de algunos de sus jugadores de forma significativa.

Sin embargo, esta regularidad en el juego a lo largo del partido no implica equilibrio entre los diferentes puestos específicos empleados. Como mostraron nuestros resultados, el jugador opuesto es el que más acciones terminales acumula de forma individual (Figura 4), sólo viéndose superado por el puesto de receptor en la clasificación por posición, es decir, cuando éste reúne los datos de ambos receptores del equipo (figura 5). Estos tres jugadores se consideran normalmente los atacantes principales de cualquier equipo. La participación de los dos receptores y los dos centrales está igualada entre sí y no hay distinción ni por su posición en la rotación, ni por su posición con respecto al colocador. Esto cuestiona la teoría que sitúa a los jugadores con más aportación en ataque adyacentes al colocador y formando un triángulo con el opuesto, jugador de mayor jerarquía en el ataque. La participación éste último en las acciones terminales, similar a la de los centrales e inferiores a los receptores (en su conjunto) no muestra la jerarquía que en teoría se ha concedido a este especialista en el voleibol masculino de alto nivel desde que apareció el sistema de ataque conocido como 5:1.

El análisis de regresión logística que relacionó el éxito en las acciones terminales con el puesto específico del jugador y la posición (zona delantera o zaguera) en el momento de ejecutar dicha acción (Tabla 25) ofreció unos resultados altamente significativos, 
demostrando que los jugadores con mayor probabilidad de conseguir puntos para sus equipos son, en orden descendente, aquéllos que ocupan los puestos de opuesto, receptor, central y colocador. Así pues, se confirmó estadísticamente lo que el análisis descriptivo sugería respecto a los atacantes principales y al opuesto en particular.

Observando la distribución de frecuencias de las acciones terminales se encuentra que el ataque es la conducta con la que finaliza una mayor cantidad de puntos (más de la mitad, según nuestros datos (Figura 20)), ya sea con éxito, confirmando su preponderancia como acción de más peso para la consecución de puntos (Häyrinen et al., 2004; Marelić et al., 2004; Palao et al., 2004a; Rodríguez-Ruiz et al., 2011; Zetou et al., 2007).

A priori, estos datos dan pie a pensar que la forma más normal de conseguir puntos es con el ataque del opuesto.

Volviendo a la tabla 25, el modelo obtenido consiguió cuantificar la diferencia de probabilidad de éxito en función de la zona en que se produzca la acción terminal, estableciéndose que existe mayor probabilidad de conseguir puntos para el equipo propio desde zona delantera que desde zona zaguera.

Sin embargo, uno de los resultados que más llama la atención es el peso menor del atacante opuesto en la zona zaguera con respecto a los demás perfiles cuando atacan en zona delantera. Esto invita a revisar la evolución del opuesto, tradicionalmente considerado como el atacante de más peso en el equipo y con una alta contribución en el ataque de zaguero para compensar la presencia en la red del colocador en tres rotaciones.

Volviendo a las acciones terminales, tras el ataque, el bloqueo y la defensa son las acciones con las que más frecuentemente finalizan los puntos. En estudios en los que se ha comparado el rendimiento entre los equipos ganadores y perdedores de los partidos (Rodríguez-Ruiz et al., 2011), el bloqueo representó la diferencia a favor del equipo ganador en los sets igualados (por encima de 25 puntos) y los quintos sets, ya que el equipo perdedor conseguía más puntos con el ataque. Respecto a la defensa, según los resultados obtenidos por Mesquita et al. (2007), una de cada tres acciones defensivas acaban en error y por tanto punto para el rival. En nuestro caso hemos encontrado que una de cada diez acciones terminales es una defensa mal ejecutada.

Entre las acciones menos decisivas encontramos el punto directo con el saque, el error en la recepción y el error en la colocación. En cuanto a ésta última, el gran nivel técnico de los colocadores, responsables de esta función, hace que sea muy poco habitual encontrar puntos perdidos a causa de la misma. Las dos primeras están relacionadas, pues el elevado rendimiento alcanzado hoy en día por los receptores y líberos, debido a la constante evolución de los sistemas de recepción, hace que se produzcan menos errores en la ejecución de esta acción, y por lo tanto sea menos frecuente la consecución de puntos de forma directa con el servicio por parte de los equipos rivales. 
Atendiendo al saque en particular, según nuestros resultados se ganan más puntos con el mismo que con errores en la recepción, lo cual difiere de lo obtenido por Marelić et al. (2004), según los que las acciones más importantes en la finalización de los puntos son, en este orden, el ataque, la recepción, el bloqueo y el saque. Sin embargo, otros estudios (García y Fernández, 2003) han encontrado una mayor relevancia del servicio, situándolo junto al bloqueo como la acción discriminante de la victoria, si bien se centraron en el quinto set de los partidos de competición europea.

Atendiendo a la tabla 20, gran cantidad de las acciones terminales negativas son defensas y recepciones. Por ello, aunque el estudio de las acciones terminales muestra al ataque como la forma más importante de puntuación y más relacionada con la victoria (Rodríguez-Ruiz et al., 2011), se considera necesario comenzar la observación a partir de las acciones anteriores, lo cual proporcionará un mayor conocimiento sobre cuánto afecta esta acción técnica a las posibilidades de tener éxito en el mismo. Esta afirmación se encuentra respaldada desde el ámbito del entrenamiento por diversos estudios, que concluyeron que los entrenadores deberían centrar los entrenamientos en la acción de la recepción, seguida del ataque en función de la misma (Häyrinen et al., 2004; Zetou et al., 2007), así como en la defensa y su conexión con el posterior ataque, dada su relación con la victoria del set (Monteiro et al., 2009; Yiannis et al., 2004).

No se encontraron resultados significativos que asociaran el desarrollo del partido con la acción terminal empleada. En el estudio de Marcelino et al. (2009), centrándose en las acciones de continuidad (recepción, colocación y defensa) encontraron que su rendimiento es inferior al principio de los partidos, para posteriormente aumentar y estabilizarse. La ausencia de significación estadística en nuestro análisis sugiere que, al igual que ocurría con la participación de los jugadores, los equipos se mantienen regulares en la forma en que consiguen o pierden sus puntos a lo largo de sus encuentros, lo que los hace menos predecibles para los rivales y es, por tanto, un indicador de rendimiento.

En lo que respecta al análisis rotacional, dadas las características del voleibol se ha encontrado una asociación altamente significativa entre el jugador que ejecuta la acción terminal, para ambas clasificaciones, y la rotación de su equipo en esa acción. Tradicionalmente se ha tomado al colocador como referencia a la hora de los estudios sobre la rotación (Palao et al., 2002), por lo que este estudio aporta información sobre el resto de jugadores que completan el equipo. Es importante reconocer las rotaciones en las que el colocador es delantero (2, 3 y 4) desde la perspectiva de la necesaria compensación de atacantes zagueros. Cabe destacar la participación mayor del receptor en zona zaguera de la rotación 2 y la participación del opuesto en las rotaciones 2 y 3 , significativamente menor. Esto implicaría una disminución del potencial de ataque en la rotación 3 y una exposición a una estrategia de saque sobre el receptor zaguero en la rotación 2. 
Teniendo en cuenta que el central es el jugador más condicionado por la calidad de la recepción para participar en ataque, posiblemente, una mayor localización del saque en esa rotación 2 sobre el receptor zaguero esté facilitando la alta participación del central en esa misma rotación. La rotación no afecta a las probabilidades de ganar un punto, por lo que podemos decir que en este nivel los equipos presentan propuestas equilibradas en la distribución de sus rotaciones.

Como se desprende de la figura 21 y tabla 22, todos los jugadores ven aumentada su participación en las acciones finales para su equipo en aquellas rotaciones que implican estar en la zona delantera (zonas 2, 3 y 4), ocurriendo lo contrario con las de la zona zaguera en las que no tienen que sacar. Así, todos los jugadores reparten alrededor $80 \%$ aproximadamente de sus acciones terminales entre esas cuatro rotaciones. Cabe reseñar que en el opuesto es en el que menos acusada se ve esta tendencia, por las razones indicadas anteriormente en cuanto a que su función principal, incluso cuando se encuentra en posiciones zagueras, es la del ataque, y como tal se ve reflejado en los datos. 


\section{Conclusiones}

El número de jugadores que intervienen en las acciones terminales no se ve alterado a medida que se desarrolla el partido de forma global, así como los sets de forma general produciéndose una excepción en la fase intermedia del primer set para algunos de los jugadores, que no parece trascendente.

La proporción con la que se dan las diferentes acciones para la obtención o pérdida de puntos se mantiene constante a lo largo del juego.

La gran mayoría de las acciones terminales son ejecutadas por los jugadores que se encuentran en la zona delantera (zonas 2, 3 y 4), por lo que la rotación ejerce un papel fundamental en la participación en las acciones finales de los equipos.

El de opuesto es el puesto específico con mayor probabilidad de realizar acciones terminales positivas, seguido por los receptores, los centrales y el colocador, pero tiene un menor peso desde la zona zaguera con respecto a los demás perfiles cuando atacan en zona delantera. 


\section{Agradecimientos}

Al Ministerio de Ciencia e Innovación, por la financiación del proyecto Sistema MasVb de Evaluación Competitiva y Orientación Técnica para la Superliga Española de Voleibol (DEP2011-27503).

A Joaquín, tanto por ser un compañero de trabajo como por mostrarme el camino a seguir.

A Pedro y María, por sus aportaciones y soluciones, sin las cuales este estudio no se habría podido llevar a cabo.

A Aurelio, para el que cualquier palabra de agradecimiento se quedaría corta. 


\section{Referencias}

Byra, M., y Scott, A. (1983). A method for recording team statistics in volleyball. Volleyball Technical Journal, 7(3), 39-44.

Clemente, J., Antonio, J., Moreno Domínguez, A., y Moreno Arroyo, P. (2005). Estudio de la relación entre la eficacia de las acciones de primer contacto y la eficacia del ataque en voleibol masculino de alto nivel. Kronos: revista universitaria de la actividad física y el deporte(8), 57-61.

Cohen, J. (1960). A coefficient of agreement for nominal scales. Educational and psychological measurement, 20(1), 37-46.

Dávila-Romero, C., y García-Hermoso, A. (2012a). Acciones finales discriminantes de voleibol en categorías de formación masculina: importancia del saque en los partidos igualados.(Discriminatory volleyball final actions in male formative stages: importance). RICYDE. Revista Internacional de Ciencias del Deporte, 8(28), 151-160.

Dávila-Romero, C., y García-Hermoso, A. (2012b). El set cerrado en voleibol. Diferencias y poder discriminatorio de las acciones finales en etapas de formación. Retos. Nuevas tendencias en Educación Física, Deporte y Recreación(21), 67-70.

Dávila-Romero, C., García-Hermoso, A., y Saavedra-García, J.M. (2012). Poder discriminatorio de las acciones finales de voleibol en etapas de formación. Revista Internacional de Medicina y Ciencias de la Actividad Física y del Deporte(48), 1010.

FIVB, Reglas Oficiales del Voleibol, 2013-2016, 2012.

Fleiss, J. (2003). Statistical methods for rates and proportions. 3rd ed. Wiley-Interscience.

García, F., y Fernández, F. (2003). Acciones determinantes en el resultado en voleibol. Estudio presentado en el Congreso Internacional sobre entrenamiento deportivo: promoción y tecnificación. Instrumentos para el desarrollo del Voleibol. Universidad de Vigo. España.

Häyrinen, M., Hoivala, T., y Blomqvist, M. (2004). Differences between winning and losing teams in men's European top-level volleyball. Estudio presentado en Proceedings of VI Conference Performance Analysis.

Hughes, M., y Daniel, R. (2003). Playing patterns of elite and non-elite volleyball. International Journal of Performance Analysis in Sport, 3(1), 50-56.

Lorenzo Calvo, A., Gómez Ruano, M.A., Ortega Toro, E., Ibañez Godoy, S.J., y Sampaio, J. (2010). Game related statistics which discriminate between winning and losing under-16 male basketball games. Journal of Sports Science and Medicine, 9(4), 664-668. 
Marcelino, R., y Mesquita, I. (2008). Associations between performance indicators and set's result on male volleyball. Estudio presentado en el 5th International Scientific Conference on Kinesiology.

Marcelino, R., Mesquita, I., y Afonso, J. (2008). The weight of terminal actions in Volleyball. Contributions of the spike, serve and block for the teams' rankings in the World League 2005. International Journal of Performance Analysis in Sport, 8(2), 1-7.

Marcelino, R., Mesquita, I., y Sampaio, J. (2009). Estudo dos indicadores de rendimento em Voleibol masculino em função do número do set. Revista Brasileira de Ciência e Movimento, 16(3).

Marcelino, R., Sampaio, J., y Mesquita, I. (2012). Attack and serve performances according to the match period an quality of opposition in elite volleyball matches. Journal of Strength and Conditioning Research, 26(12), 3385-3391.

Marelić, N., Rešetar, T., y Janković, V. (2004). Discriminant analysis of the sets won and the sets lost by one team in A1 Italian volleyball league-A case study. Kineziologija, 36(1), 75-82.

Mesquita, I., Manso, F.D., y Palao, J.M. (2007). Defensive participation and efficacy of the libero in volleyball. Journal of Human Movement Studies, 52(2), 95-108.

Monteiro, R., Mesquita, I., y Marcelino, R. (2009). Relationship between the set outcome and the dig and attack efficacy in elite male Volleyball game. International Journal of Performance Analysis in Sport, 9(3), 294-305.

Palao, J.M., Santos, J.A., y Ureña, A. (2002). Incidencia del rendimiento de los complejos de juego por rotaciones sobre la clasificación final de los JJOO de Sydney 2000. Valladolid: Real Federación Española de Voleibol, 8.

Palao, J.M., Santos, J.A., y Ureña, A. (2004a). Effect of team level on skill performance in volleyball. International Journal of Performance Analysis in Sport, 4(2), 50-60.

Palao, J.M., Santos, J.A., y Ureña, A. (2004b). Effect of the setter's position on block in volleyball. International Journal of Volleyball Research, 6(1) 29-32.

Palao, J.M., Santos, J.A., y Ureña, A. (2005). The effect of the setter's position on the spike in volleyball. Journal of Human Movement Studies, 48(1), 25-40.

Rodríguez-Ruiz, D., Quiroga, M.E., Miralles, J.A., Sarmiento, S., de Saá, Y., y García-Manso, J.M. (2011). Study of the technical and tactical variables determining set win or loss in top-level European Men's Volleyball. Journal of Quantitative Analysis in Sports, 7(1).

Sampaio, J. (1998). Los indicadores estadisticos más determinantes en el resultado final en los partidos de basquetbol. Lecturas: Educación Física y Deportes, 3(11).

Santos, J.A. (1992). Estudio sobre las variaciones en el rendimiento en equipos de voleibol de élite a través de la información obtenida mediante un sistema estadístico 
informatizado. Tesis doctoral del Departamento de Personalidad, Evaluación y Tratamiento Psicológico. Universidad de Granada.

Ureña, A., Vavassori, R., León-Rodríguez, J., y González-Ortiz, M. (2011). Efecto del saque en suspensión sobre la construcción del ataque en el voleibol.(Jump serve incidence on the attack phase in the Spanish under-14 volleyball). RICYDE. Revista Internacional de Ciencias del Deporte, 7(26), 384-392.

Ureña, A., Morales, J.S., León, J. y González, M. (en prensa). El voleibol español infantil. Estudio del nivel de participación en el juego. Revista Internacional de Medicina y Ciencias de la Actividad Física y el Deporte.

Yiannis, L., Panagiotis, K., Ioannis, A., y Alkinoi, K. (2004). A comparative study of the effectiveness of the Greek national men's Volleyball team with internationally topranked teams. International Journal of Volleyball Research, 1(1), 4.

Zetou, E., Moustakidis, A., Tsigilis, N., y Komninakidou, A. (2007). Does effectiveness of skill in complex I predict win in men's olympic volleyball games. Journal of Quantitative Analysis in Sports, 3(4), 1-9. 
Análisis de la participación de los jugadores de voleibol masculino de alto nivel mundial en las acciones terminales del juego

\section{Anexos}


Tabla 1. Distribución de frecuencias del puesto específico del jugador que realizó la acción en función del periodo del set. Clasificación de los jugadores por función.

\begin{tabular}{|c|c|c|c|c|c|c|c|c|c|c|c|}
\hline & \multicolumn{10}{|c|}{ Periodo del set } & \multirow{2}{*}{ Total } \\
\hline & $1-5$ & $6-10$ & $11-15$ & $16-20$ & $21-25$ & $26-30$ & $31-35$ & $36-40$ & $41-45$ & $>46$ & \\
\hline Colocador & 45 & 51 & 63 & 41 & 46 & 46 & 48 & 44 & 41 & 20 & 445 \\
\hline Receptor Adyacente & 106 & 127 & 138 & 143 & 105 & 109 & 139 & 124 & 86 & 59 & 1136 \\
\hline Central Alejado & 95 & 65 & 87 & 89 & 88 & 60 & 83 & 82 & 55 & 33 & 737 \\
\hline Opuesto & 170 & 166 & 152 & 164 & 166 & 171 & 162 & 160 & 131 & 71 & 1513 \\
\hline Receptor Alejado & 136 & 121 & 103 & 121 & 127 & 124 & 102 & 120 & 109 & 47 & 1110 \\
\hline Central Adyacente & 81 & 77 & 76 & 61 & 89 & 77 & 68 & 58 & 71 & 32 & 690 \\
\hline Líbero & 10 & 24 & 14 & 16 & 16 & 21 & 23 & 16 & 10 & 9 & 159 \\
\hline Total & 643 & 631 & 633 & 635 & 637 & 608 & 625 & 604 & 503 & 271 & 5790 \\
\hline
\end{tabular}

Tabla 2. Distribución de frecuencias del puesto específico del jugador que realizó la acción en función del periodo del set. Clasificación de los jugadores por posición.

\begin{tabular}{|c|c|c|c|c|c|c|c|c|c|c|c|}
\hline & \multicolumn{10}{|c|}{ Periodo del set } & \multirow{2}{*}{ Total } \\
\hline & $1-5$ & $6-10$ & $11-15$ & $16-20$ & $21-25$ & $26-30$ & $31-35$ & $36-40$ & $41-45$ & $>46$ & \\
\hline Colocador & 45 & 51 & 63 & 41 & 46 & 46 & 48 & 44 & 41 & 20 & 445 \\
\hline Opuesto & 170 & 166 & 152 & 164 & 166 & 171 & 162 & 160 & 131 & 71 & 1513 \\
\hline Receptor & 242 & 248 & 241 & 264 & 232 & 233 & 241 & 244 & 195 & 106 & 2246 \\
\hline Central & 176 & 142 & 163 & 150 & 177 & 137 & 151 & 140 & 126 & 65 & 1427 \\
\hline Líbero & 10 & 24 & 14 & 16 & 16 & 21 & 23 & 16 & 10 & 9 & 159 \\
\hline Total & 643 & 631 & 633 & 635 & 637 & 608 & 625 & 604 & 503 & 271 & 5790 \\
\hline
\end{tabular}


Tabla 3. Distribución de frecuencias del jugador (clasificación por función) que realizóla acción según el periodo del set, teniendo en cuenta los primeros sets.

\begin{tabular}{|c|c|c|c|c|c|c|c|c|c|c|c|}
\hline \multirow{2}{*}{ SET 1} & \multicolumn{10}{|c|}{ Periodo del set } & \multirow{2}{*}{ Total } \\
\hline & $1-5$ & $6-10$ & $11-15$ & $16-20$ & $21-25$ & $26-30$ & $31-35$ & $36-40$ & $41-45$ & $>46$ & \\
\hline Colocador & 7 & 15 & 15 & 10 & 10 & 10 & 12 & 10 & 11 & 5 & 105 \\
\hline Receptor Adyacente & 38 & 32 & 36 & 33 & 28 & 25 & 40 & 41 & 24 & 11 & 308 \\
\hline Central Alejado & 20 & 13 & 27 & 32 & 20 & 11 & 26 & 19 & 12 & 7 & 187 \\
\hline Opuesto & 37 & 48 & 39 & 45 & 44 & 46 & 49 & 41 & 31 & 16 & 396 \\
\hline Receptor Alejado & 38 & 34 & 22 & 24 & 37 & 41 & 24 & 26 & 29 & 8 & 283 \\
\hline Central Adyacente & 24 & 14 & 20 & 14 & 21 & 21 & 15 & 17 & 25 & 2 & 173 \\
\hline Líbero & 1 & 7 & 5 & 2 & 3 & 7 & 5 & 7 & 4 & 2 & 43 \\
\hline Total & 165 & 163 & 164 & 160 & 163 & 161 & 171 & 161 & 136 & 51 & 1495 \\
\hline
\end{tabular}

Tabla 4. Distribución de frecuencias del jugador (clasificación por función) que realizó la acción según el periodo del set, teniendo en cuenta los segundos sets.

\begin{tabular}{|c|c|c|c|c|c|c|c|c|c|c|c|}
\hline \multirow{2}{*}{ SET 2} & \multicolumn{10}{|c|}{ Periodo del set } & \multirow{2}{*}{ Total } \\
\hline & $1-5$ & $6-10$ & $11-15$ & $16-20$ & $21-25$ & $26-30$ & $31-35$ & $36-40$ & $41-45$ & $>46$ & \\
\hline Colocador & 14 & 15 & 18 & 9 & 17 & 10 & 18 & 14 & 7 & 2 & 124 \\
\hline Receptor Adyacente & 25 & 36 & 39 & 35 & 23 & 27 & 35 & 33 & 30 & 8 & 291 \\
\hline Central Alejado & 25 & 21 & 22 & 23 & 28 & 14 & 23 & 23 & 15 & 12 & 206 \\
\hline Opuesto & 51 & 38 & 38 & 41 & 43 & 48 & 36 & 47 & 31 & 11 & 384 \\
\hline Receptor Alejado & 35 & 34 & 33 & 34 & 35 & 37 & 26 & 39 & 27 & 6 & 306 \\
\hline Central Adyacente & 18 & 24 & 16 & 16 & 28 & 26 & 24 & 16 & 16 & 5 & 189 \\
\hline Líbero & 3 & 8 & 5 & 3 & 4 & 7 & 7 & 4 & 3 & 2 & 46 \\
\hline Total & 171 & 176 & 171 & 161 & 178 & 169 & 169 & 176 & 129 & 46 & 1546 \\
\hline
\end{tabular}


Tabla 5. Distribución de frecuencias del jugador (clasificación por función) que realizó la acción según el periodo del set, teniendo en cuenta los terceros sets.

\begin{tabular}{|c|c|c|c|c|c|c|c|c|c|c|c|}
\hline \multirow{2}{*}{ SET 3} & \multicolumn{10}{|c|}{ Periodo del set } & \multirow{2}{*}{ Total } \\
\hline & $1-5$ & $6-10$ & $11-15$ & $16-20$ & $21-25$ & $26-30$ & $31-35$ & $36-40$ & $41-45$ & $>46$ & \\
\hline Colocador & 17 & 7 & 15 & 10 & 9 & 13 & 9 & 12 & 12 & 10 & 114 \\
\hline Receptor Adyacente & 22 & 30 & 37 & 45 & 30 & 35 & 36 & 31 & 20 & 27 & 313 \\
\hline Central Alejado & 34 & 20 & 21 & 15 & 24 & 19 & 26 & 28 & 16 & 8 & 211 \\
\hline Opuesto & 47 & 44 & 45 & 44 & 50 & 45 & 48 & 43 & 44 & 29 & 439 \\
\hline Receptor Alejado & 32 & 33 & 29 & 38 & 27 & 26 & 32 & 34 & 30 & 25 & 306 \\
\hline Central Adyacente & 25 & 23 & 23 & 13 & 27 & 21 & 16 & 12 & 20 & 16 & 196 \\
\hline Líbero & 1 & 7 & 1 & 7 & 3 & 5 & 6 & 4 & 2 & 4 & 40 \\
\hline Total & 178 & 164 & 171 & 172 & 170 & 164 & 173 & 164 & 144 & 119 & 1619 \\
\hline
\end{tabular}

Tabla 6. Distribución de frecuencias del jugador (clasificación por función) que realizó la acción según el periodo del set, teniendo en cuenta los cuartos sets.

\begin{tabular}{|c|c|c|c|c|c|c|c|c|c|c|c|}
\hline \multirow{2}{*}{ SET 4} & \multicolumn{10}{|c|}{ Periodo del set } & \multirow{2}{*}{ Total } \\
\hline & $1-5$ & $6-10$ & $11-15$ & $16-20$ & $21-25$ & $26-30$ & $31-35$ & $36-40$ & $41-45$ & $>46$ & \\
\hline Colocador & 7 & 12 & 11 & 10 & 9 & 11 & 9 & 8 & 11 & 3 & 91 \\
\hline Receptor Adyacente & 21 & 25 & 18 & 20 & 20 & 19 & 28 & 19 & 12 & 13 & 195 \\
\hline Central Alejado & 12 & 10 & 11 & 18 & 15 & 14 & 8 & 12 & 12 & 6 & 118 \\
\hline Opuesto & 28 & 29 & 22 & 27 & 24 & 29 & 29 & 29 & 25 & 15 & 257 \\
\hline Receptor Alejado & 23 & 14 & 16 & 18 & 22 & 18 & 20 & 21 & 23 & 8 & 183 \\
\hline Central Adyacente & 6 & 9 & 15 & 13 & 9 & 8 & 13 & 13 & 10 & 9 & 105 \\
\hline Líbero & 3 & 2 & 1 & 2 & 5 & 2 & 5 & 1 & 1 & 1 & 23 \\
\hline Total & 100 & 101 & 94 & 108 & 104 & 101 & 112 & 103 & 94 & 55 & 972 \\
\hline
\end{tabular}


Tabla 7. Distribución de frecuencias del jugador (clasificación por función) que realizó la acción según el periodo del set, teniendo en cuenta los quintos sets.

\begin{tabular}{|c|c|c|c|c|c|c|c|}
\hline \multirow{2}{*}{ SET 5} & \multicolumn{6}{|c|}{ Periodo del set } & \multirow{2}{*}{ Tota } \\
\hline & $1-5$ & $6-10$ & $11-15$ & $16-20$ & $21-25$ & $>26$ & \\
\hline Colocador & 0 & 2 & 4 & 2 & 1 & 2 & 11 \\
\hline Receptor Adyacente & 0 & 4 & 8 & 10 & 4 & 3 & 29 \\
\hline Central Alejado & 4 & 1 & 6 & 1 & 1 & 2 & 15 \\
\hline Opuesto & 7 & 7 & 8 & 7 & 5 & 3 & 37 \\
\hline Receptor Alejado & 8 & 6 & 3 & 7 & 6 & 2 & 32 \\
\hline Central Adyacente & 8 & 7 & 2 & 5 & 4 & 1 & 27 \\
\hline Líbero & 2 & 0 & 2 & 2 & 1 & 0 & 7 \\
\hline Total & 29 & 27 & 33 & 34 & 22 & 13 & 158 \\
\hline
\end{tabular}

Tabla 9. Distribución de frecuencias del jugador (clasificación por posición) que ejecutó la acción según el periodo del set, teniendo en cuenta los primeros sets.

\begin{tabular}{|c|c|c|c|c|c|c|c|c|c|c|c|}
\hline \multirow{2}{*}{ SET 1} & \multicolumn{10}{|c|}{ Periodo del set } & \multirow{2}{*}{ Total } \\
\hline & $1-5$ & $6-10$ & $11-15$ & $16-20$ & $21-25$ & $26-30$ & $31-35$ & $36-40$ & $41-45$ & $>46$ & \\
\hline Colocador & 7 & 15 & 15 & 10 & 10 & 10 & 12 & 10 & 11 & 5 & 105 \\
\hline Opuesto & 37 & 48 & 39 & 45 & 44 & 46 & 49 & 41 & 31 & 16 & 396 \\
\hline Receptor & 76 & 66 & 58 & 57 & 65 & 66 & 64 & 67 & 53 & 19 & 591 \\
\hline Central & 44 & 27 & 47 & 46 & 41 & 32 & 41 & 36 & 37 & 9 & 360 \\
\hline Líbero & 1 & 7 & 5 & 2 & 3 & 7 & 5 & 7 & 4 & 2 & 43 \\
\hline Total & 165 & 163 & 164 & 160 & 163 & 161 & 171 & 161 & 136 & 51 & 1495 \\
\hline
\end{tabular}


Tabla 10. Distribución de frecuencias del jugador (clasificación por posición) que ejecutó la acción según el periodo del set, teniendo en cuenta los segundos sets.

\begin{tabular}{|c|c|c|c|c|c|c|c|c|c|c|c|}
\hline \multirow{2}{*}{ SET 2} & \multicolumn{10}{|c|}{ Periodo del set } & \multirow{2}{*}{ Total } \\
\hline & $1-5$ & $6-10$ & $11-15$ & $16-20$ & $21-25$ & $26-30$ & $31-35$ & $36-40$ & $41-45$ & $>46$ & \\
\hline Colocador & 14 & 15 & 18 & 9 & 17 & 10 & 18 & 14 & 7 & 2 & 124 \\
\hline Opuesto & 51 & 38 & 38 & 41 & 43 & 48 & 36 & 47 & 31 & 11 & 384 \\
\hline Receptor & 60 & 70 & 72 & 69 & 58 & 64 & 61 & 72 & 57 & 14 & 597 \\
\hline Central & 43 & 45 & 38 & 39 & 56 & 40 & 47 & 39 & 31 & 17 & 395 \\
\hline Líbero & 3 & 8 & 5 & 3 & 4 & 7 & 7 & 4 & 3 & 2 & 46 \\
\hline Total & 171 & 176 & 171 & 161 & 178 & 169 & 169 & 176 & 129 & 46 & 1546 \\
\hline
\end{tabular}

Tabla 11. Distribución de frecuencias del jugador (clasificación por posición) que ejecutó la acción según el periodo del set, teniendo en cuenta los terceros sets.

\begin{tabular}{|c|c|c|c|c|c|c|c|c|c|c|c|}
\hline \multirow{2}{*}{ SET 3} & \multicolumn{10}{|c|}{ Periodo del set } & \multirow{2}{*}{ Total } \\
\hline & $1-5$ & $6-10$ & $11-15$ & $16-20$ & $21-25$ & $26-30$ & $31-35$ & $36-40$ & $41-45$ & $>46$ & \\
\hline Colocador & 17 & 7 & 15 & 10 & 9 & 13 & 9 & 12 & 12 & 10 & 114 \\
\hline Opuesto & 47 & 44 & 45 & 44 & 50 & 45 & 48 & 43 & 44 & 29 & 439 \\
\hline Receptor & 54 & 63 & 66 & 83 & 57 & 61 & 68 & 65 & 50 & 52 & 619 \\
\hline Central & 59 & 43 & 44 & 28 & 51 & 40 & 42 & 40 & 36 & 24 & 407 \\
\hline Líbero & 1 & 7 & 1 & 7 & 3 & 5 & 6 & 4 & 2 & 4 & 40 \\
\hline Total & 178 & 164 & 171 & 172 & 170 & 164 & 173 & 164 & 144 & 119 & 1619 \\
\hline
\end{tabular}


Tabla 12. Distribución de frecuencias del jugador (clasificación por posición) que ejecutó la acción según el periodo del set, teniendo en cuenta los cuartos sets.

\begin{tabular}{|c|c|c|c|c|c|c|c|c|c|c|c|}
\hline \multirow{2}{*}{ SET 4} & \multicolumn{10}{|c|}{ Periodo del set } & \multirow{2}{*}{ Tota } \\
\hline & $1-5$ & $6-10$ & $11-15$ & $16-20$ & $21-25$ & $26-30$ & $31-35$ & $36-40$ & $41-45$ & $>46$ & \\
\hline Colocador & 7 & 12 & 11 & 10 & 9 & 11 & 9 & 8 & 11 & 3 & 91 \\
\hline Opuesto & 28 & 29 & 22 & 27 & 24 & 29 & 29 & 29 & 25 & 15 & 257 \\
\hline Receptor & 44 & 39 & 34 & 38 & 42 & 37 & 48 & 40 & 35 & 21 & 378 \\
\hline Central & 18 & 19 & 26 & 31 & 24 & 22 & 21 & 25 & 22 & 15 & 223 \\
\hline Líbero & 3 & 2 & 1 & 2 & 5 & 2 & 5 & 1 & 1 & 1 & 23 \\
\hline Total & 100 & 101 & 94 & 108 & 104 & 101 & 112 & 103 & 94 & 55 & 972 \\
\hline
\end{tabular}

Tabla 13. Distribución de frecuencias del jugador (clasificación por posición) que ejecutó la acción según el periodo del set, teniendo en cuenta los quintos sets.

\begin{tabular}{cccccccc}
\hline \multirow{2}{*}{ SET 5 } & \multicolumn{9}{c}{ Periodo del set } & Total \\
\cline { 2 - 7 } & $\mathbf{1 - 5}$ & $\mathbf{6 - 1 0}$ & $\mathbf{1 1 - 1 5}$ & $\mathbf{1 6 - 2 0}$ & $\mathbf{2 1 - 2 5}$ & $\mathbf{2 6}$ & \\
\hline Colocador & 0 & 2 & 4 & 2 & 1 & 2 & 11 \\
\hline Opuesto & 7 & 7 & 8 & 7 & 5 & 3 & 37 \\
\hline Receptor & 8 & 10 & 11 & 17 & 10 & 5 & 61 \\
\hline Central & 12 & 8 & 8 & 6 & 5 & 3 & 42 \\
\hline Líbero & 2 & 0 & 2 & 2 & 1 & 0 & 7 \\
\hline Total & 29 & 27 & 33 & 34 & 22 & 13 & 158 \\
\hline
\end{tabular}


Tabla 14. Distribución de frecuencias del puesto específico del jugador, en su clasificación por función, que realizó la acción según el periodo del partido.

\begin{tabular}{|c|c|c|c|c|c|c|c|c|c|c|c|}
\hline & \multicolumn{10}{|c|}{ Periodo del partido } & \multirow{2}{*}{ Total } \\
\hline & $1-18$ & $19-36$ & $37-54$ & $55-72$ & $73-90$ & $91-108$ & $109-126$ & $127-144$ & $145-162$ & $>162$ & \\
\hline Colocador & 45 & 38 & 42 & 54 & 53 & 39 & 40 & 34 & 42 & 58 & 445 \\
\hline Receptor Adyacente & 123 & 116 & 114 & 120 & 122 & 118 & 121 & 89 & 83 & 130 & 1136 \\
\hline Central Alejado & 79 & 75 & 73 & 83 & 73 & 94 & 79 & 63 & 40 & 78 & 737 \\
\hline Opuesto & 153 & 161 & 164 & 145 & 151 & 159 & 175 & 131 & 91 & 183 & 1513 \\
\hline Receptor Alejado & 110 & 114 & 114 & 128 & 125 & 110 & 106 & 100 & 63 & 140 & 1110 \\
\hline Central Adyacente & 64 & 70 & 74 & 73 & 81 & 73 & 77 & 49 & 42 & 87 & 690 \\
\hline Líbero & 14 & 19 & 19 & 14 & 22 & 16 & 14 & 14 & 10 & 17 & 159 \\
\hline Total & 588 & 593 & 600 & 617 & 627 & 609 & 612 & 480 & 371 & 693 & 5790 \\
\hline
\end{tabular}

Tabla 15. Distribución de frecuencias del puesto específico del jugador, en su clasificación por posición, que realizó la acción según el periodo del partido.

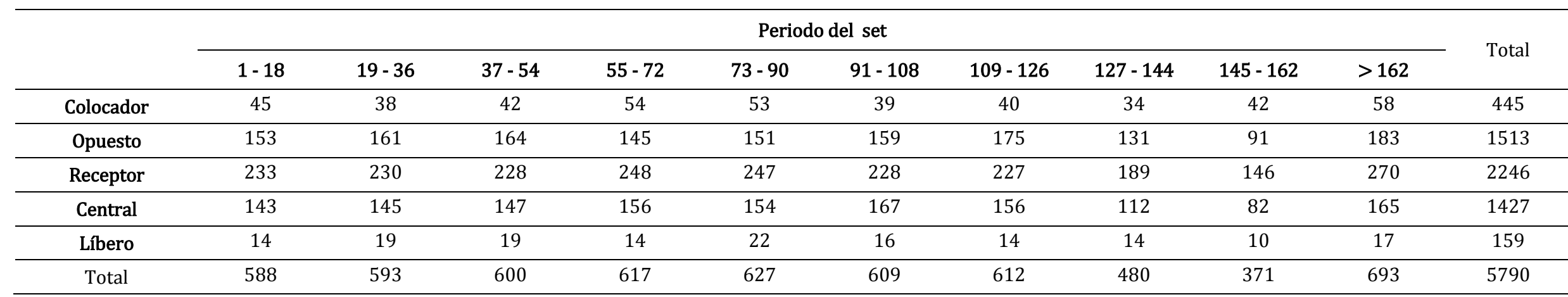


Tabla 16. Distribución de frecuencias del jugador, clasificado por función, que realizó la acción terminal positiva según el periodo del partido.

\begin{tabular}{|c|c|c|c|c|c|c|c|c|c|c|c|}
\hline & \multicolumn{10}{|c|}{ Periodo del partido } & \multirow{2}{*}{ Total } \\
\hline & $1-18$ & $19-36$ & $37-54$ & $55-72$ & $73-90$ & $91-108$ & $109-126$ & $127-144$ & $145-162$ & $>162$ & \\
\hline Colocador & 6 & 6 & 8 & 18 & 17 & 13 & 11 & 13 & 13 & 12 & 117 \\
\hline Receptor Adyacente & 68 & 62 & 59 & 67 & 62 & 60 & 61 & 42 & 49 & 72 & 602 \\
\hline Central Alejado & 44 & 42 & 27 & 37 & 47 & 49 & 42 & 29 & 17 & 36 & 370 \\
\hline Opuesto & 90 & 80 & 87 & 74 & 81 & 83 & 102 & 79 & 51 & 106 & 833 \\
\hline Receptor Alejado & 65 & 60 & 66 & 60 & 71 & 63 & 57 & 53 & 29 & 66 & 590 \\
\hline Central Adyacente & 28 & 32 & 39 & 43 & 38 & 37 & 35 & 21 & 25 & 50 & 348 \\
\hline Total & 301 & 282 & 286 & 299 & 316 & 305 & 308 & 237 & 184 & 342 & 2860 \\
\hline
\end{tabular}

Tabla 17. Distribución de frecuencias del jugador, clasificado por posición, que realizó la acción terminal positiva según el periodo del partido.

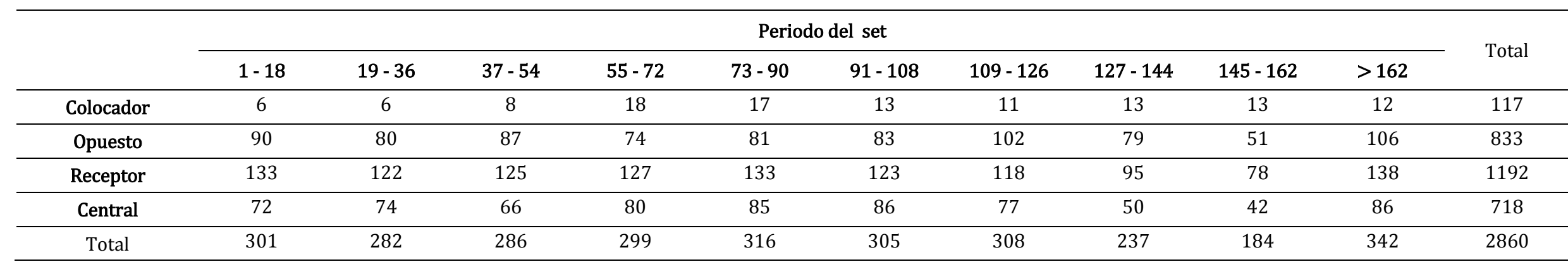


Tabla 18. Distribución de frecuencias del jugador, clasificado por función, que ejecutó la acción terminal negativa según el periodo del partido.

\begin{tabular}{|c|c|c|c|c|c|c|c|c|c|c|c|}
\hline & \multicolumn{10}{|c|}{ Periodo del partido } & \multirow{2}{*}{ Total } \\
\hline & $1-18$ & $19-36$ & $37-54$ & $55-72$ & $73-90$ & $91-108$ & $109-126$ & $127-144$ & $145-162$ & $>162$ & \\
\hline Colocador & 39 & 32 & 34 & 36 & 36 & 26 & 29 & 21 & 29 & 46 & 328 \\
\hline Receptor Adyacente & 55 & 54 & 55 & 53 & 60 & 58 & 60 & 47 & 34 & 58 & 534 \\
\hline Central Alejado & 35 & 33 & 46 & 46 & 26 & 45 & 37 & 34 & 23 & 42 & 367 \\
\hline Opuesto & 63 & 81 & 77 & 71 & 70 & 76 & 73 & 52 & 40 & 77 & 680 \\
\hline Receptor Alejado & 45 & 54 & 48 & 68 & 54 & 47 & 49 & 47 & 34 & 74 & 520 \\
\hline Central Adyacente & 36 & 38 & 35 & 30 & 43 & 36 & 42 & 28 & 17 & 37 & 342 \\
\hline Líbero & 14 & 19 & 19 & 14 & 22 & 16 & 14 & 14 & 10 & 17 & 159 \\
\hline Total & 287 & 311 & 314 & 318 & 311 & 304 & 304 & 243 & 187 & 351 & 2930 \\
\hline
\end{tabular}

Tabla 19. Distribución de frecuencias del jugador, clasificado por posición, que ejecutó la acción terminal negativa según el periodo del partido.

\begin{tabular}{|c|c|c|c|c|c|c|c|c|c|c|c|}
\hline & \multicolumn{10}{|c|}{ Periodo del set } & \multirow{2}{*}{ Total } \\
\hline & $1-18$ & $19-36$ & $37-54$ & $55-72$ & $73-90$ & $91-108$ & $109-126$ & $127-144$ & $145-162$ & $>162$ & \\
\hline Colocador & 39 & 32 & 34 & 36 & 36 & 26 & 29 & 21 & 29 & 46 & 328 \\
\hline Opuesto & 63 & 81 & 77 & 71 & 70 & 76 & 73 & 52 & 40 & 77 & 680 \\
\hline Receptor & 100 & 108 & 102 & 121 & 114 & 105 & 109 & 93 & 70 & 132 & 1054 \\
\hline Central & 71 & 71 & 81 & 76 & 69 & 81 & 79 & 62 & 40 & 79 & 709 \\
\hline Líbero & 14 & 19 & 19 & 14 & 22 & 16 & 14 & 14 & 10 & 17 & 159 \\
\hline Total & 287 & 311 & 313 & 318 & 311 & 304 & 304 & 242 & 187 & 351 & 2930 \\
\hline
\end{tabular}


Tabla 20. Distribución de frecuencias del tipo de acción terminal que tuvo lugar en cada periodo del partido.

\begin{tabular}{|c|c|c|c|c|c|c|c|c|c|c|c|}
\hline & \multicolumn{10}{|c|}{ Periodo del partido } & \multirow{2}{*}{ Total } \\
\hline & $1-18$ & $19-36$ & $37-54$ & $55-72$ & $73-90$ & 91 - 108 & $109-126$ & $127-144$ & $145-162$ & $>162$ & \\
\hline Saque\# & 18 & 11 & 16 & 18 & 13 & 24 & 18 & 15 & 12 & 13 & 158 \\
\hline Saque $=$ & 63 & 84 & 78 & 62 & 55 & 58 & 65 & 44 & 41 & 74 & 624 \\
\hline Recepción= & 10 & 6 & 11 & 9 & 6 & 18 & 12 & 10 & 9 & 10 & 101 \\
\hline Colocación $=$ & 7 & 4 & 5 & 9 & 5 & 2 & 3 & 4 & 6 & 4 & 49 \\
\hline Ataque\# & 240 & 230 & 232 & 238 & 253 & 236 & 245 & 180 & 145 & 278 & 2277 \\
\hline Ataque $=$ & 86 & 84 & 79 & 86 & 87 & 89 & 83 & 74 & 47 & 95 & 810 \\
\hline Bloqueo\# & 43 & 41 & 38 & 43 & 50 & 45 & 45 & 42 & 27 & 51 & 425 \\
\hline Bloqueo $=$ & 67 & 61 & 82 & 88 & 80 & 73 & 89 & 71 & 43 & 90 & 744 \\
\hline Defensa $=$ & 54 & 71 & 58 & 64 & 77 & 61 & 52 & 39 & 41 & 78 & 595 \\
\hline Otros\# & 0 & 0 & 1 & 0 & 0 & 0 & 0 & 1 & 0 & 0 & 2 \\
\hline Otros $=$ & 0 & 1 & 0 & 0 & 1 & 3 & 0 & 0 & 0 & 0 & 5 \\
\hline Total & 588 & 593 & 600 & 617 & 627 & 609 & 612 & 480 & 371 & 693 & 5790 \\
\hline
\end{tabular}

